
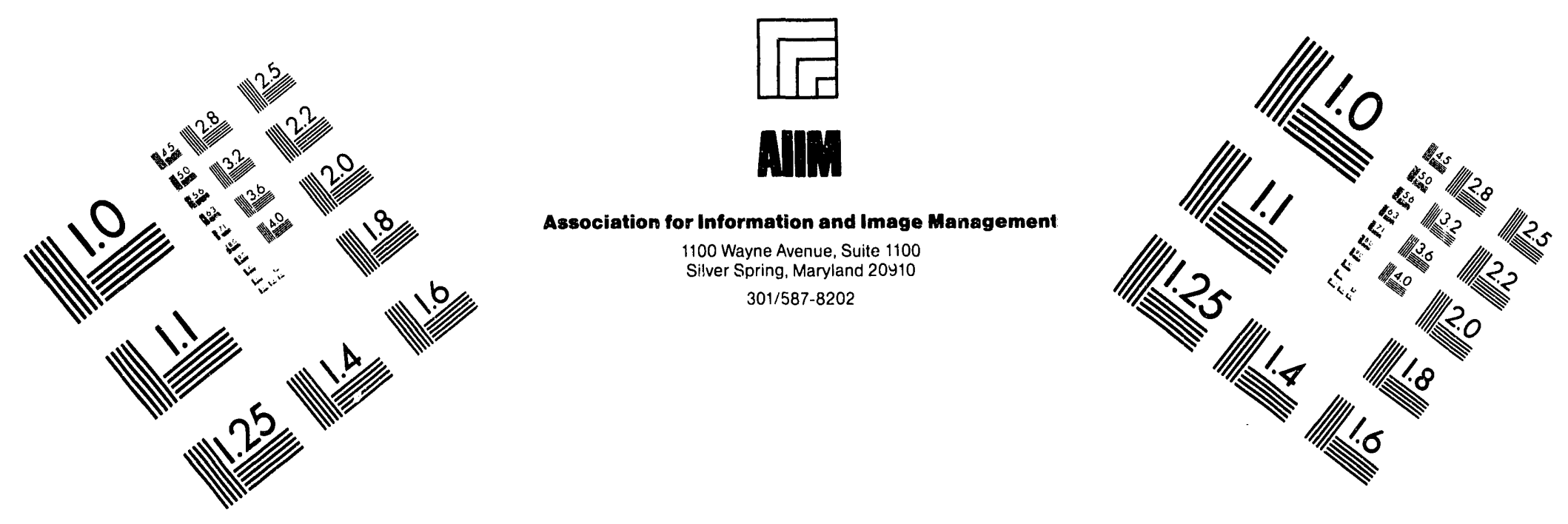

\title{
Centimeter
}

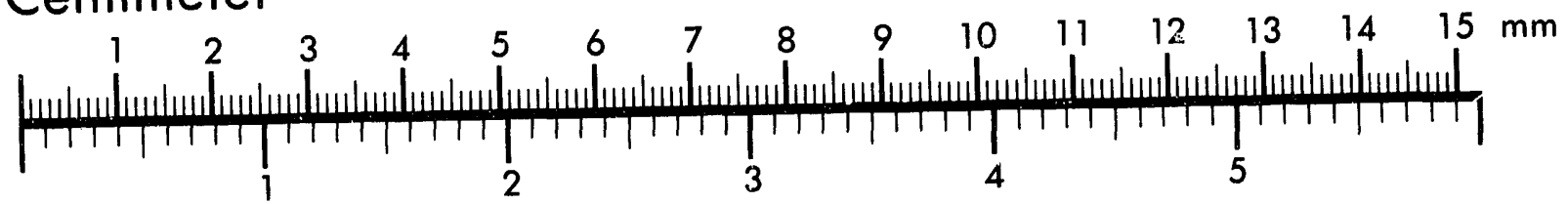

Inches
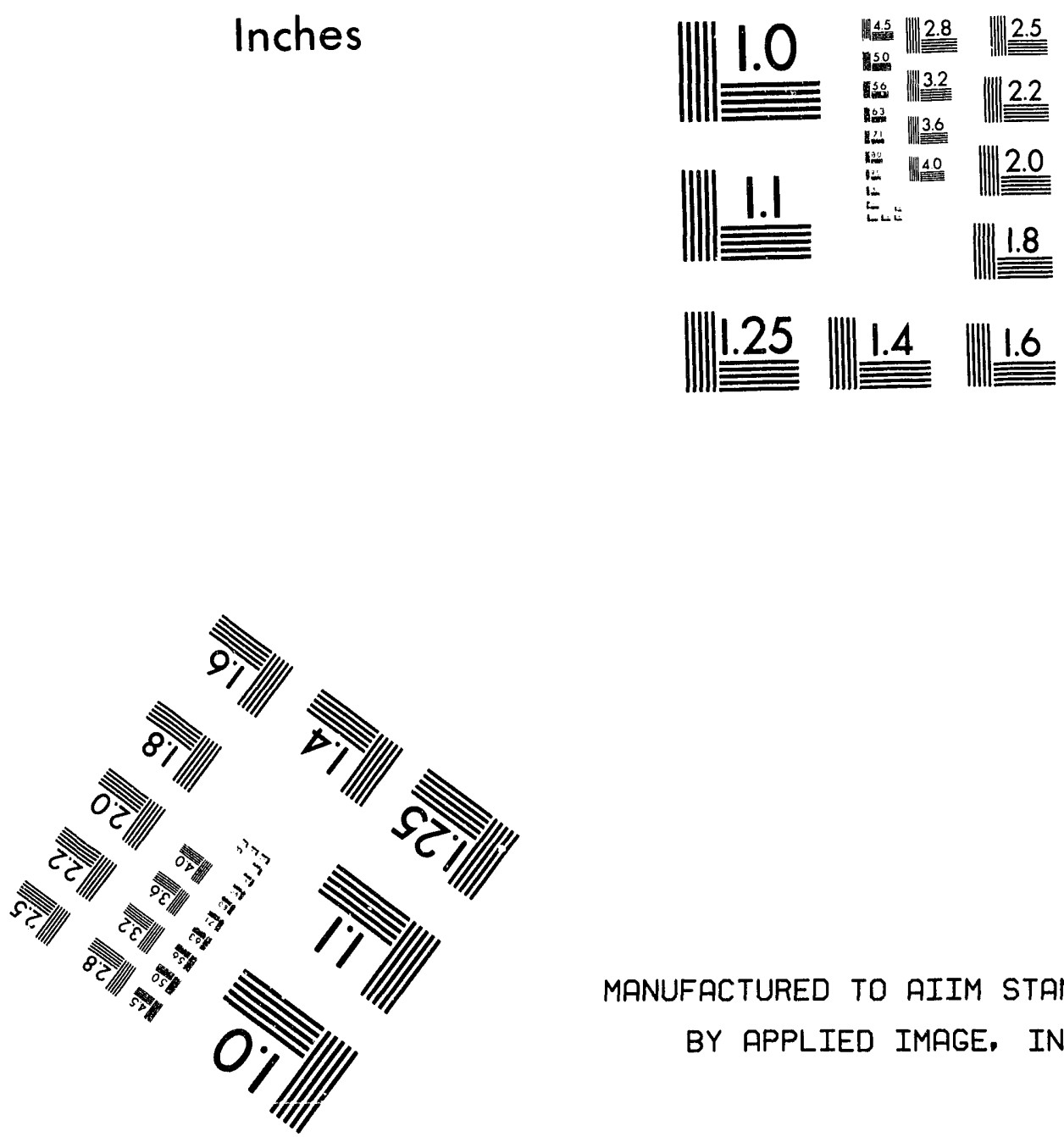

MANUFACTURED TO AIIM STANDARDS

BY APPLIED IMAGE, INC.

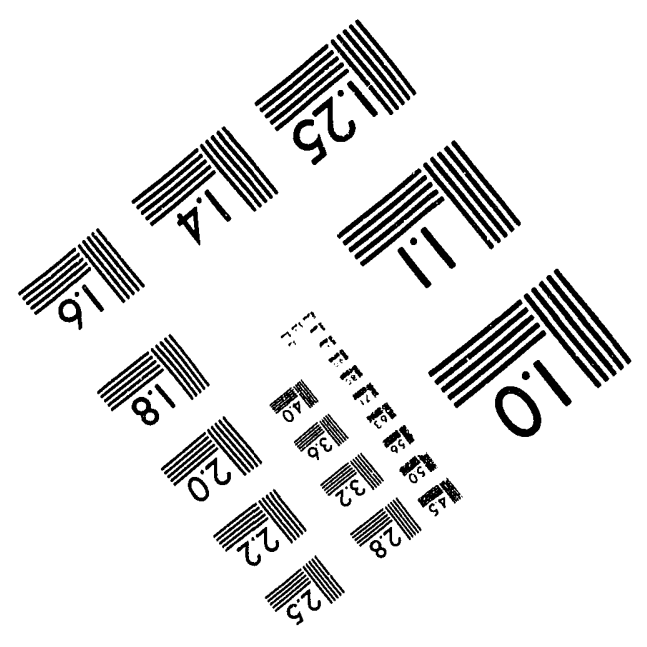



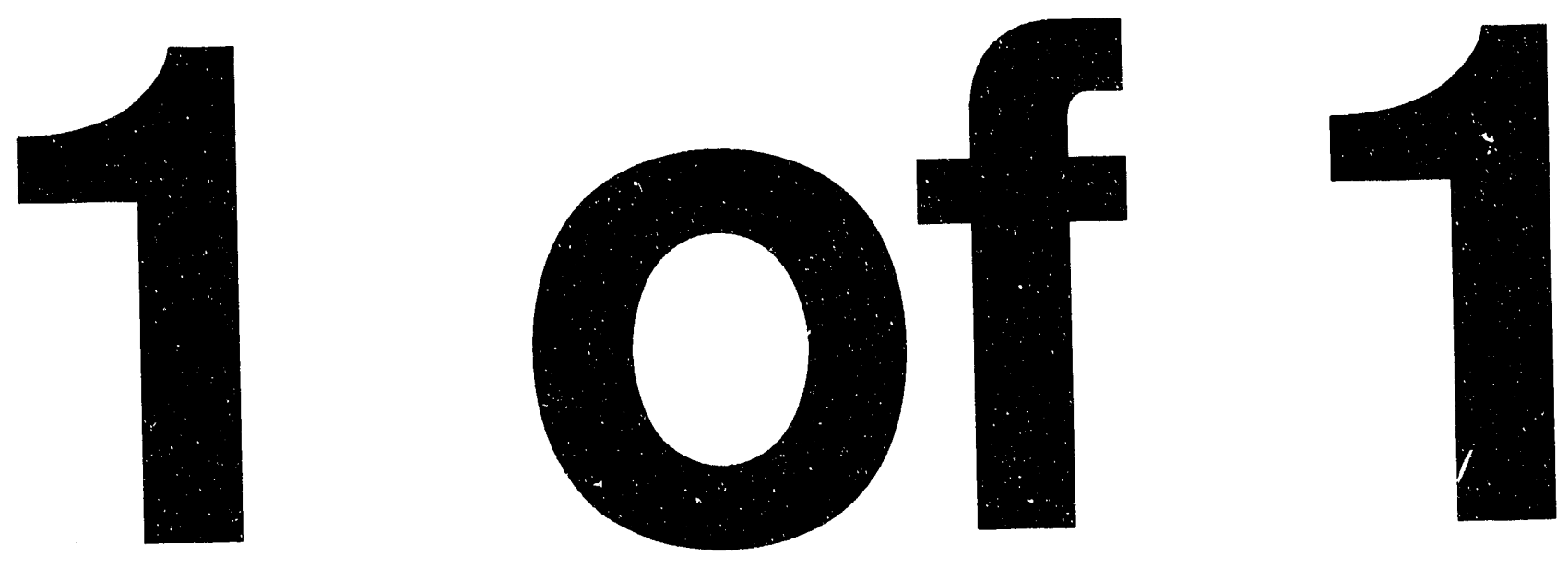


\section{SURVEY OF \\ SUBSURFACE GEOPHYSICAL EXPLORATION TECHNOL.OGIES ADAPTABLE TO AN AIRBORNE PLATFORM}

K. A. Taylor

Principal Investigator

K. W. Forcade

Project Scientist



This Document is UNCLASSIFIED

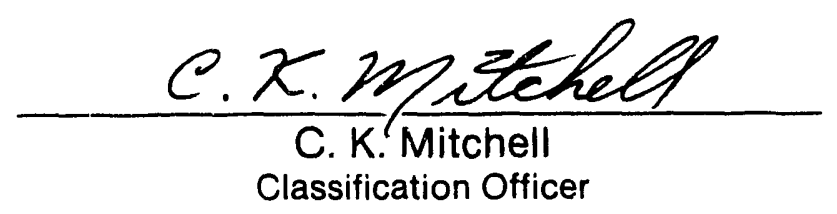

This work was performed by EG\&G/EM for the United States Department of Energy under Contract Number DE-AC08-88NV10617. 


\begin{abstract}
This report has been prepared by the U.S. Department of Energy (DOE) as part of a Research Development Demonstration Testing and Evaluation (RDDT\&E) project by EG\&G Energy Measurement's (EG\&G/EM) Remote Sensing Laboratory. It examines geophysical detection techniques which may be used in Environmental Restoration/Waste Management (ERMM) surveys to locate buried waste, waste containers, potential waste migratory paths, and aquifer depths. Because of the Remote Sensing Laboratory's unique survey capabilities, only those technologies which have been adapted or are capable of being adapted to an airborne platform were studied.

This survey describes several of the available subsurface survey technologies and discusses the basic capabilities of each: the target detectability, required geologic conditions, and associated survey methods. Because the airborne capabilities of these survey techniques have not been fully developed, the chapters deal mostly with the ground-based capabilities of each of the technologies, with reference made to the airborne capabilities where applicable. The information about each survey technique came from various contractors whose companies employ these specific technologies. EG\&G/EM cannot guarantee or verify the accuracy of the contractor information; however, the data given is an indication of the technologies that are available.
\end{abstract}




\section{CONTENTS}

Abstract

\section{Sections}



2.0 Electromagnetic Inductive Survey Method $\ldots \ldots \ldots \ldots \ldots \ldots \ldots \ldots \ldots \ldots \ldots \ldots$

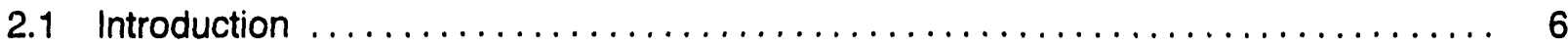



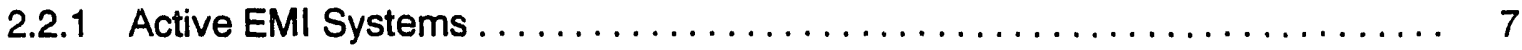

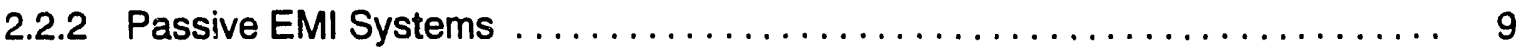

2.3 Nature of the Measurements $\ldots \ldots \ldots \ldots \ldots \ldots \ldots \ldots \ldots \ldots \ldots \ldots \ldots \ldots \ldots$

2.4 Target Type and Detectability $\ldots \ldots \ldots \ldots \ldots \ldots \ldots \ldots \ldots \ldots \ldots \ldots \ldots \ldots \ldots$

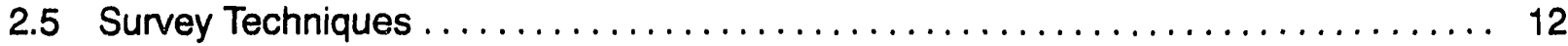

2.6 Associated Technologies $\ldots \ldots \ldots \ldots \ldots \ldots \ldots \ldots \ldots \ldots \ldots \ldots \ldots \ldots \ldots$

2.7 Questions to ask EMI Survey Contractors $\ldots \ldots \ldots \ldots \ldots \ldots \ldots \ldots \ldots \ldots \ldots \ldots$

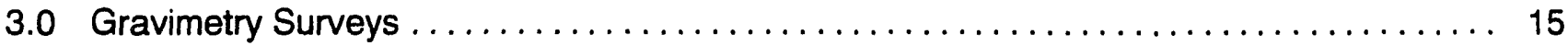



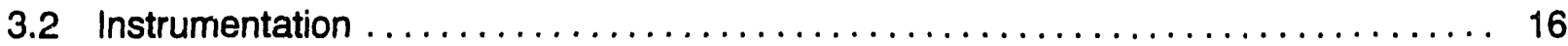

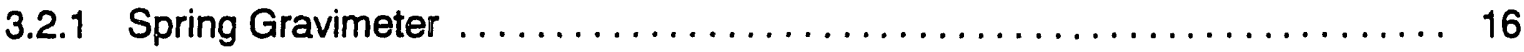

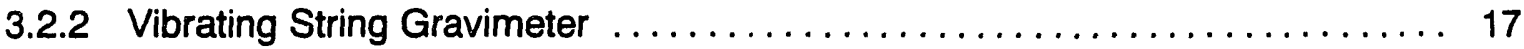



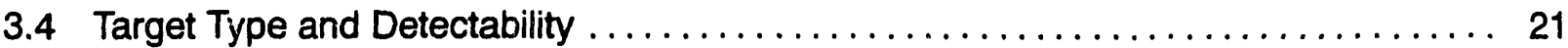



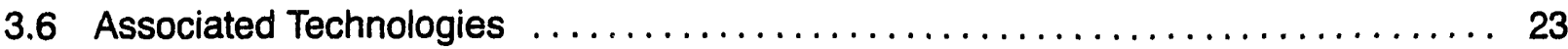

3.7 Questions to ask Survey Contractors $\ldots \ldots \ldots \ldots \ldots \ldots \ldots \ldots \ldots \ldots \ldots \ldots$

4.0 Ground-Penetrating Radar Surveys $\ldots \ldots \ldots \ldots \ldots \ldots \ldots \ldots \ldots \ldots \ldots \ldots \ldots \ldots \ldots$

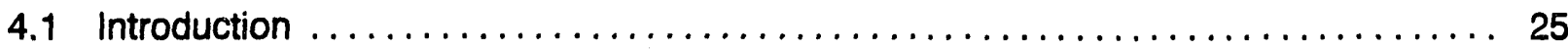


4.2 Instrumentation $\ldots \ldots \ldots \ldots \ldots \ldots \ldots \ldots \ldots \ldots \ldots \ldots \ldots \ldots \ldots \ldots \ldots \ldots \ldots \ldots \ldots \ldots \ldots \ldots \ldots, 25$





4.2 .3 Output $\ldots \ldots \ldots \ldots \ldots \ldots \ldots \ldots \ldots \ldots \ldots \ldots \ldots \ldots \ldots \ldots \ldots \ldots \ldots \ldots, 27$



4.4 Target Type and Detectability $\ldots \ldots \ldots \ldots \ldots \ldots \ldots \ldots \ldots \ldots \ldots \ldots \ldots \ldots \ldots \ldots, 29$

4.5 Survey Techniques $\ldots \ldots \ldots \ldots \ldots \ldots \ldots \ldots \ldots \ldots \ldots \ldots \ldots \ldots \ldots \ldots \ldots \ldots, 29$

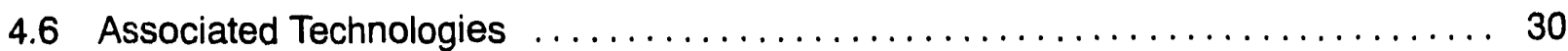

4.7 Questions to ask Survey Contractors $\ldots \ldots \ldots \ldots \ldots \ldots \ldots \ldots \ldots \ldots \ldots \ldots \ldots \ldots \ldots$

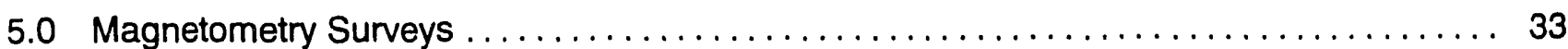

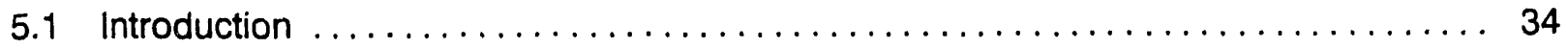

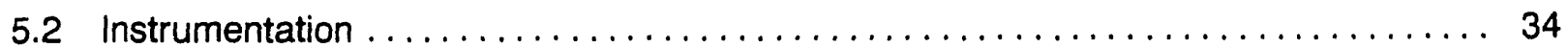

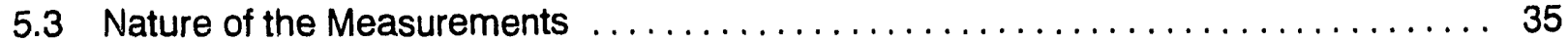



5.3.2 Effects of Magnetosphere and lonosphere $\ldots \ldots \ldots \ldots \ldots \ldots \ldots \ldots . \ldots . \ldots . \ldots$

5.3.3 Anomalies ........................................... 37

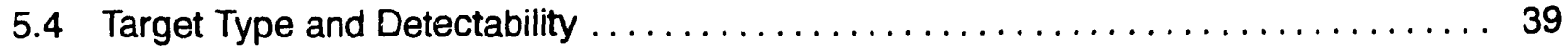

5.5 Survey Techniques ...................................... 40

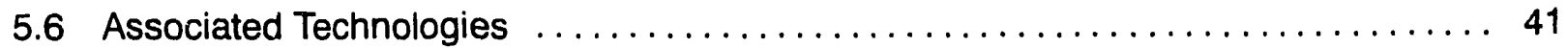

5.7 Questions to ask Survey Contractors $\ldots \ldots \ldots \ldots \ldots \ldots \ldots \ldots \ldots \ldots \ldots \ldots, 41$

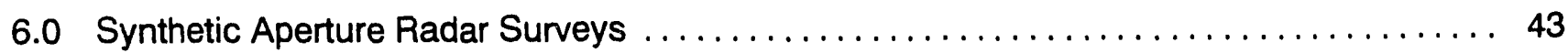

6.1 Introduction ............................................. 44



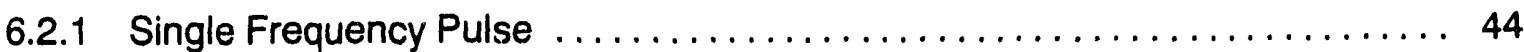

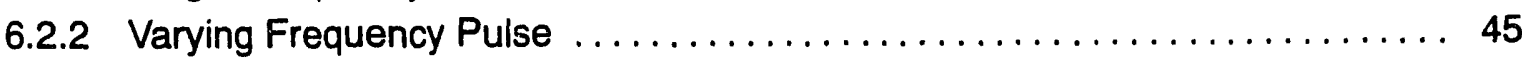

6.2.3 Determining Resolution Capability .......................... 45

6.2.4 Azimuthal Resolution and Synthetic Aperture ................... 46

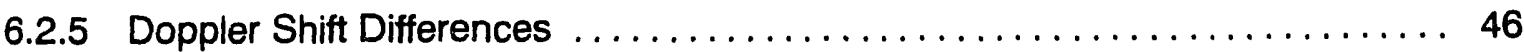

6.2.6 Phase Shift ......................................... 47

6.2.7 Transmitter and Receiver Polarization $\ldots \ldots \ldots \ldots \ldots \ldots \ldots \ldots \ldots, 49$

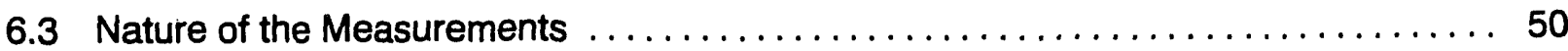

6.3 .1 Terrain Effects .......................................... 50

6.3.2 Target Composition and Size ............................ 50

6.3.3 Target Limiting and Determining Factors $\ldots \ldots \ldots \ldots \ldots \ldots \ldots \ldots \ldots, 51$ 


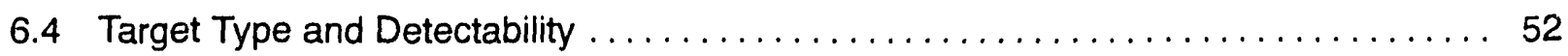



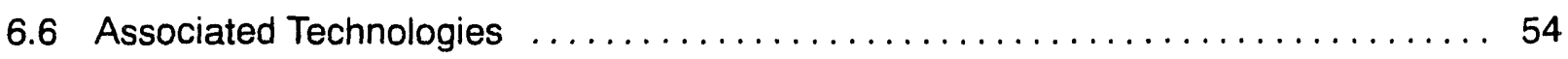

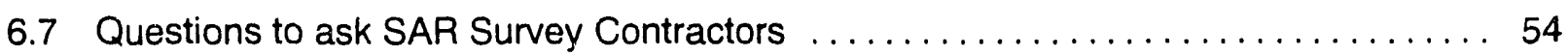

\section{Figures}

1 Coil Configuration for Transmitter and Receiver $\ldots \ldots \ldots \ldots \ldots \ldots \ldots \ldots \ldots \ldots$



3 Highly Exaggerated Representation of the Difference Between the Geoid

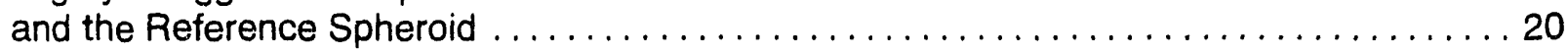

4 Transmitted Electromagnetic Pulses and Target Echo $\ldots \ldots \ldots \ldots \ldots \ldots \ldots \ldots \ldots \ldots$

5 Representation of Earth's Magnetic Field . . . . . . . . . . . . . . . . . . . . . . . . . 36



7 Large-Area Disturbance: Diurnal Variation .............................. 37

8 Included Magnetization: Changing an Ambient Field ........................ 38

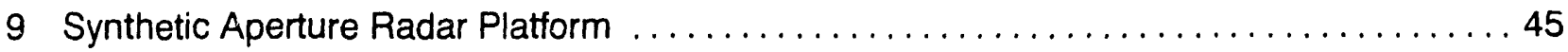



11 Sinusoidal Electromagnetic Pulse Representation $\ldots \ldots \ldots \ldots \ldots \ldots \ldots \ldots \ldots \ldots$

12 Distance Variances ............................................ 49

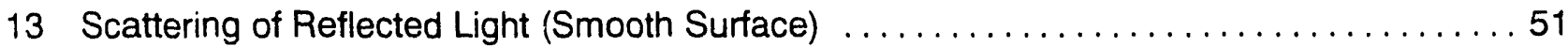

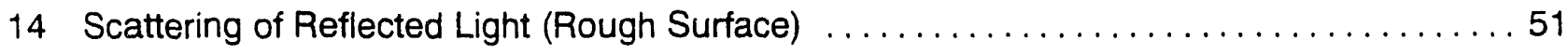

15 EMP Reflection from Two Hills with Shadow Time Indicated ................... 53

\section{Tables}



2 A pproximate Magnetic Strength of Objects with Differing Am Junts of Iron Content ........................................ 40

\section{Appendices}

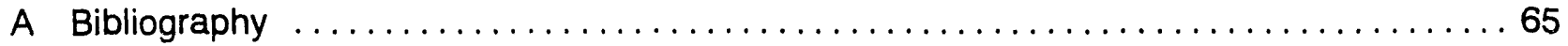

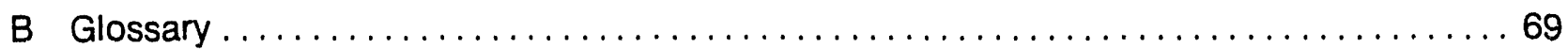

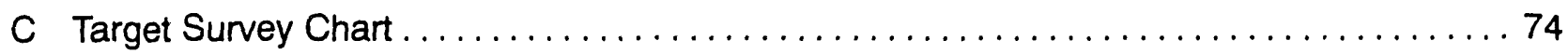

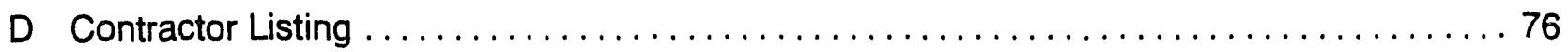




\subsection{EXECUTIVE SUMMARY}




\section{EXECUTIVE SUMMARY}

The following detection technologies may be used in Environmental Restoration/Waste Management (ERMM) surveys to locate buried waste, waste containers, potential waste migratory paihs, and aquifer depths.

\section{Electromagnetic Inductive Methods}

Electromagnetic Inductive (EMI) methods measure and interpret the changes in an electromagnetic field caused by variations in the electrical properties of the surrounding soil. EMI methods can be used to find buried metallic drums, hazardous waste plumes, and the most effective locations for sampling wells. Often, a survey employing EMI technologies can determine the boundary and composition of landfills.

EMI equipment mounted on an aerial platform can detect targets at depths in the range of 300 meters. A small, mobile, ground-based system can detect targets at depths to approximately 50 meters, and a large, fixed-coil survey could examine depths up to a 1,000 meters.

The optimum conditions for using EMI detection technologies are those in which a target or volume of soil with high conductivity is located in a large subsurface area of low conductivity. EMI techniques do not work well in areas of high soil conductivity or if there is a large amount of metallic surface debris. Metal buildings or power lines near the survey area can severely degrade the quality of the collected data. Often a survey will use EMI detection techniques first and then use magnetometry or groundpenetrating radar technologies to examine a specific area of anomalous readings more closely.

\section{Gravimetry}

Gravimetry detection technology is based on the study of the force of gravity, its variations, and the causes of the variations. Gravimetry can be used to determine large-scale geologic structures, large near-surface tunnels, and changes in subsurface soil density which might indicate the direction of contamination migration or the boundaries of a landfill. In surveys, portable relative measurement gravimeters determine the change in gravity field strength from one position to another. The spring gravimeter and the vibrating string gravimeter are the two types of instruments most commonly used.

The chief purpose of a gravimetry survey is to determine large changes in soil density. Therefore, gravimetry is not an appropriate technology for storage tank or waste drum searches. Conditions such as large near-surface tunnels or caverns, the alluvial-bedrock interface, or the depth to the local aquifer have been deternined by ground-based gravimetry. Aircraft-based gravimetry has been used to find large-scale :argets such as salt domes and deep sea trenches.

Aircraft-based surveys can only detect targets that are several kilometers in size; therefore, it is doubtful that aerial surveys would yield adequate results with the finely detailed resolution needed in ER/ WM surveys. Other technologies which might be used in conjunction with gravimetry techniques include seismic surveys (for determining soil density changes) and EMI surveys to determine the depth to the local aquifer.

\section{Ground-Penetrating Radar}

Ground-Penetrating Radar (GPR) technology is used to fully map a subsurface environment. GPR can be used to find metal objects or hydrocarbon plumes, to determine the depth to the water table, or to determine specific geologic feath es of the subsurface soil strata or bedrock. 
The GPR is a radar system which emits an electromagnetic pulse of short duration. The system then analyzes the echo return of the pulse to determine subsurface conditions and detect objects. Two major characteristics determine the depth of detectability: the frequency of the radar system's pulse and the conductivity of the soil. The lower the frequency of the electromagnetic pulse, the deeper the penetration into the soil. GPR systems are designed to operate at frequencies between 80 and 900 $\mathrm{MHz}$.

In conductive soils (soils which are salty and wet or have a high clay content), the depth of detectability can be less than one meter. However, in nonconductive soil conditions, such as dry, sandy soils, the depth of detectability can be as much as $\mathbf{5 0}$ meters with resolutions superior to any other subsurface geophysical exploration technique.

Ground-based GPR systems claim a depth of detectability to 50 meters with a resolution of 10 centimeters; airborne systems claim a 20-meter depth of detectability and a 20-centimeter resolution, under the best conditions. GPR is typically used to more closely examine an area which is suspected of containing a target. This suspicion can be based on prior knowledge of the area or on anomalous readings from a magnetometry or EMI survey.

\section{Magnetometry}

Magnetometry detection technology is used in surveys to find objects which alter the earth's magnetic fields. It can be used to find magnetic materials, some landfills, and some hydrocarbon-saturated soils.

There are two methods of magnetometry detection: the gradient technique and the total-field technique. The gradient technique employs two magnetometers; a stronger reading on one magnetometer indicates a nearby object with strong magnetic qualities. The total-field technique measures the total magnetic field at each point along a survey grid. The data are then analyzed for any indication of the presence of subsurface, iron-based, or magnetic targets. Although the survey and data analysis techniques involved are similar for both types of magnetometry surveys, total-field surveys provide a more complete analysis of the subsurface conditions.

Magnetometry techniques can only be used to locate targets which have some magnetic characteristics, such as steel drums or some soils which have been exposed to hydrocarbons. Given certain soil conditions, magnetometry can be used to search for the boundaries of hydrocarbon plumes.

Magnetometry cannot be used to find nonmagnetic objects such as aluminum or pollutants which do not cause a change in the magnetic characteristics of the soil.

Ideally, a magnetometry survey should be conducted in an area free of iron debris and with soil of low magnetic characteristics. Highly magnetic soils or nearby iron or magnetic objects can render the survey data useless.

The distance from a magnetometer, either airborne or ground-based, at which a targei may be detected is as small as 3 to 4 meters for a single 55-gallon drum or as great as 100 meters for a steel ship hull.

\section{Synthetic Aperture Radar}

Synthetic Aperture Radar (SAR) is a side-looking imaging radar used to map large areas of terrain, inventory vegetative types and conditions, and determine the extent of oil spills at sea. Some 
subsurface investigation is possible with this technology; however, its greatest advantage is its ability to image through forest and thick vegetative canopies. Abandoned stockpiles of drums and industrial equipment could be found with this technology, but usually it is used to map terrain conditions and topography so that some determination of waste pollutant presence and migration direction is possible.

SAR systems can be mounted on aircraft, satellites, and even in the space shuttle. Resolutions are from 1.5 meters by 1.5 meters for an aircraft-based system to 15 meters by 15 meters for commercial satellite systems. SAR is a radar technique, and as such, targets might be hidden due to weather conditions. For a high frequency system, rain might absorb or significantly scatter the radar pulse to the point that targets might be hidden. Aerial photography, laser induced florescence, and X-ray spectroscopy can also be used to complement the various capabilities of SAR. 


\subsection{ELECTROMAGNETIC INDUCTIVE SURVEY METHODS}




\section{ELECTROMAGNETIC INDUCTIVE SURVEY METHODS}

\section{Synopsis}

Technology: Electromagnetic Inductive Methods

May Detect: Buried metal drums

Hazardous waste plumes

Sampling well locations

Some types of landfills

Underlying Principle: Alteration of characteristics of electromagnetic fields caused by nearby conductive material

Optimum Geologic Conditions: Highly conductive target located in soil of low conductivity

\section{Extended Discussion}

\subsection{Introduction}

Electromagnetic Inductive (EMI) survey methods measure and interpret the changes in an electromagnetic field caused by the electrical properties of the surrounding soil and anything contained in the soil. EMI methods can be used to locate: buried metallic drums, hazardous waste plumes, effective locations for sampling wells, and, often, the boundary and composition of landfills. Traditionally, EMI methods have been used in geophysical prospecting to find concentrations of metallic ores. However, EMI methods have been employed in environmental surveys for approximately the past nine years.

\subsection{Instrumentation}

All electromagnetic inductive systems operate with the same basic principles and consist of three main components: a transmitter, the sampled volume (the conductive half-space), and a receiver.

The transmitter (usually a coil of wire) creates an electromagnetic field which is referred to as the primary field. There are two types of primary fields: a fluctuating, continuous wave signal field (the frequency domain) or a single pulse of electromagnetic energy (time domain). The conductive half-space is the volume of soil below and between the transmitter and the receiver coils. The effect it has on the primary field depends on soil characteristics. The EMI system receiver (also a coil of wire) measures the characteristics of this electromagnetic field at the point of the receiver.

EMI detection sy stems explore the survey area for targets which would cause sharp variations in soil conductivity, for example, any metal objects, ore bodies, or variations in the soil density or moisture content. The primary field reacts with the conducting material and creates a current flow within this material which, in turn, creates a secondary electromagnetic field. The higher the conductivity, the greater the secondary electromagnetic field is. These two fields interact, and the combined electromagnetic field is referred to as the total, or resultant, field. After the total electromagnetic field is 
measured by the receiving circuitry, a determination of the cause(s) of the subsurface conductivity can be made.

Transmitters operate at various frequencies. For example, one transmitter operates at 0.075 hertz and is used for deep (1,000 meters) geological investigations; another transmi cer operates at 900 to 32,000 hertz and gathers information on near-surface conditions or metal objects. The transmitter's frequency determines the depth of investigation; the lower the frequency, the greater the depth of penetration of the electromagnetic field. However, soil conditions determine the depth of detectability. Even with a transmitter of very low frequency, if the upper layers of soil are very conductive, then lower layers of soil or metal objects may be masked from investigation. Conductive overburden is a term used when the upper layers of soil are extremely conductive.

Two common classes of electromagnetic survey equipment can be used in environmental work: active and passive EMI systems. An active system uses a transmitter which is in the immediate vicinity of, or located at, the survey site. The transmitter and the receiver can be easily moved or relocated several times during the survey. Passive EMI systems use very distant, fixed-location transmitters.

Airborne EMI detection systems are usually self-contained uni's, flown either inside the aircraft (usually a helicopter), attached directly to the fuselage in a pod, or installed in a "bird" (a torpedo-like cylinder) which is connected to the helicopter by a tow line. During an aerial survey, both an active and a passive EMI system can be flown together, thus allowing more information to be gathered in a single survey flight.

\subsubsection{Active EMI Systems}

Active EMI systems are best suited for environmental survey work because the transmitter location is completely controlled by the survey team. In airborne systems, the transmitter normally accompanies the receiver in flight. In active EMI systems, which are ground-based, the transmitter can either be mobile to cover small sites or fixed in one location for large-area surveys. For the large-area surveys, a transmitter is positioned in a set location and the receiving coil is positioned at consecutive, pre-established points along a survey pattern. Readings are then taken to examine the subsurface of a survey area.

There are two general groups of active EMI systems: the frequency domain and the time domain.

\section{Frequency Domain EMI systems}

Frequency domain EMI systems have the capability of continuously recording data as the system itself is being moved over the survey site. Frequency domain systems are best used for shallow investigations of less than 30 meters. An advantage of this system is its ability to produce higher resolution images of the survey area by changing the coil orientations and the frequencies transmitted. This determines the type of targets that are indicated and the depths of penetration that are achieved.

Figure 1 illustrates the four basic configurations for the active transmitter and receiver coil pairs and their physical placement relative to each other. Although certain configurations are thought to be best for specific targets, a horizontal coplanar configuration is best for detecting metal objects near the surface, and vertical configurations are less sensitive to metallic surface debris. Survey results, however, are strongly influenced by the relative capabilities of the surveyor's and their data reduction methods (Sinha, 1973). Therefore, it is incumbent upon the site manager to investigate the survey contractor's knowledge and experience with EMI techniques. Questions to aid the site manager in contractor evaluation are found in Section 2.7 of this chapter. 





Airborne active EMI systems are almost exclusively the frequency domain tope, and their primary use is in sounding surveys. In a sounding survey, the subsurface between the transmitter and the receiver coils is examined with different frequencies to determine conditions at various depths.

In an active EMI frequency domain system, the transmitted frequency determines the penetration depth of the electromagnetic signal and calculates the dimensions of a conducting volume (such as a concentration of metallic ores or an aquifer). The electromagnetic field strength and frequency affects the amount of current that flows in the conductor. In a good conductor, a very high frequency will induce a current that flows only around the object's outer surface, thus limiting the amount of current flowing. The more current, the greater the secondary field produced. The secondary field's strength and frequency are compared in making calculations to increase the systems's resolution and to estimate the conductivity and volume of a conductor.

\section{Time Domain EMI Systems}

The time domain, or transient, EMI system provides greater depth of penetration in conductive environments and records data at discrete intervals. The time domain systems are best used for investigations that are at depths of greater than 50 meters.

By transmitting a pulse of electromagnetic energy instead of a continuous signal, the surrounding earth is energized, causing eddy currents in the conductive areas to form, thereby producing a secondary electromagnetic field. The transmitter is then turned off, and the receiver measures the secondary field for brief moments (windows) at predetermined times. A good conductor will have a large current which takes a longer time to dissipate than the surrounding poorly conductive soil.

The longer the response to the energy pulse lasts, the better the conductor. A shallowly buried conductor will give back a stronger response. Comparisons of these two measurements allows for the depth of the target to be estimated. The time domain EMI system's advantages are its simple design (since there is no filtering needed to compare the secondary and primary fields) and its lesser sensitivity to the site's overburden. However, the lack of filtering equipment means there is no way to eliminate any unwanted signals from power lines or surface debris. Therefore, time domain EMI systems are best used for deep surveys in rural areas.

\subsubsection{Passive EMI Systems}

The passive EMI system is a very low frequency (VLF) system which uses an electromagnetic signal that is transmitted for other purposes than the survey. The transmitters are a part of a worldwide radio network used to communicate with submarines, and VLF refers to the frequency range on which these transmitters operate (between five and twenty-five kilohertz [Telford, et al., 1976]).

VLF EMI systems use these pre-existing, distant radio stations as transmitters with each station operating on a separately assigned frequency. Unless a survey site is located where it can not receive a measurable signal, the receiving antenna in a passive survey will be tuned to receive the signal from two or more stations. The optimal situation would be to choose two stations that are close enough to receive a measurable signal and whose directions from the antenna form a $90^{\circ}$ angle.

In ideal conditions if a target is very near the transmitters, a detectability depth of 150 meters is possible. The higher the conductivity of the soil, the more shallow the penetration. The techniques used to measure the signal are similar to those used in the frequency domain active EMI system.

Both airborne and ground-based types of passive EMI systems are available for surveys. The airborne system will continually record data. A continuously recording ground system is possible, but the survey sites are usually small enough for a discrete number of data points to be measured and used in a software analysis of the area. 
In geophysical surveys, VLF EMI survey techniques are used to confirm the location of geological structures such as faults, fractures, and other near-vertical conductors. In environmental work, they can indicate the most probable paths leachate and other fluids would take to migrate off site or into the ground water aquifer. This technique can be a valuable alternative when contaminants are not directly detectable.

The passive VLF EMI system is considered a subordinate survey method to active EMI survey techniques because of the need to receive two separate stations' signals from appropriate directions. A qualitative interpretation is obtainable if only one signal is received, but two signals are necessary for a calculation of an object's conductivity and depth. Acquiring ine measurable signal is usually not a problem, but often the second signal is too weak to measure accurately. Best results are obtained if the stations are located so there is a $90^{\circ}$ angle between the received signals. These conditions do not exist in all areas; however, VLF systems require a minimal amount of time to set up, acquire readings, and interpret the data, thus making the passive EMI system a complementary method to the other geophysical techniques being used in an environmental survey.

\subsection{Nature of the Measurements}

A conductor is ariy object which readily allows an electrical current to flow (such as soil containing a high metal ore content or a metal object). Soil conductivity is chiefly determined by the porosity and salinity of the interstitial fluid (the fluid in the cracks and pores of the soil) as well as the specific mineral content of the soil. For example, wet sands are more conductive than dry sands because of their higher water content. By itself, fresh water is only moderately conductive, but salt water or wet soils with a heavy salt content are very conductive.

When a conductive soil, or a metal object in the soil, is subjected to a time-variant electromagnetic field, a current forms in this soil or object which, in turn, forms an electromagnetic field referred to as a secondary field. By measuring a secondary field at a number of points in a survey, a determination of subsurface conductivity can be made. In geophysical surveys, the unit of measurement for conductivity is the milli-mho or $1 / 1000$ of a mho.

Artificial sources of increased or anomalous conductivity include some hazardous wastes, steel drums, and the material used to fill in trenches or landfills; these become the survey targets. However, nearby objects such as metal buildings, fences, or utility lines (referred to as "cultural noise") may also be detected. An EMI survey altempts to deterrnine subsurface and anomalous conductivity by measuring the amplitude of the secondary field which is produced in the conductive half-space between the receiving coil and the transmitting coil. The effects of cultural noise can negate the effective use of EMI techniques in some areas.

An electromagnetic field has two components: the in-phase (real) component and the out-of-phase or quadrature (imaginary) component. The relationship between these components is used to calculate the effect of conductive material or, the primary electromagnetic field. These components are also used to measure the phase shift between the secondary field and the primary field, which provides useful data on the conductivity of the target or the soil.

When a fluctuating secondary electromagnetic field is created, it is in opposition to the field which created it (the primary field). The amplitude of the secondary field will reach a maximum at a point in time which does not correspond to the time when the amplitude of the primary field reaches its maximum. The difference in time is called a phase shift.

This phase shift of the resultant field (the combined primary and secondary field measured by the receiving coil) depends on the relative opposition of the secondary field as well as on the amplitude of 
the secondary field. For some targets or volumes of soil which are only slightly conductive, the resultant field will be less opposing.

The amplitude of the secondary and the resultant fields will differ depending on the type of conductor and the distance to the conductor. Once the phase and amplitude of the resultant field are known, its two components (in-phase and quadrature) can be calculated. The in-phase amplitude indicates metallic objects, and the quadrature amplitude gives a measurement of the soil's conductivity.

One method of measuring the in-phase and quadrature amplitudes is to use the transmitter's primary magnetic field as a reference. Once a reference is established, then phase filters are used to separate the primary and secondary received signals as well as the real and quadrature signals. First, the inphase and quadrature amplitudes are measured in quantitative terms such as in units of parts per million (ppm) of the primary field. This quantifies the response of the underlying soil. These values are then entered into a variety of software models to calculate the conductivity and depth of the conductor in the soil.

By comparing the responses of the two amplitudes, it is possible to determine whether the anomalous object is directly underneath or lying off to a side of a survey point. With an EMI system, a general three-dimensional image of an anomaly can be approximated, which is a useful tool for the initial assessment of a survey site.

\subsection{Target Type and Detectability}

Under proper geologic conditions, EMI survey systems can detect metal objects, contamination plumes, landfill boundaries, and the proper sites for water sampling wells. The typas of targets and their maximum detection depth are all dependent on site-specific factors. For active EMI systems, a general guideline is: airborne systems have a marimum resolvable depth of 1-300 meters (Dighem, 1971); small mobile ground units have a maximum resolvable depth of 60 meters; and large transmitter loop, ground-based systems may have depths of deieciability greater than 600 meters. (Benson, et al.,1984).

Three factors determine the maximum depth at which targets may be detected. The first factor is the sensitivity of the receiver to field changes. A receiver coil with a large radius will detect smaller objects and at greater depths, but is less accurate in determining the target's exact location. A second factor is the distance between transmitter and receiver coils which affects the resolution and depth of penetration. A larger coil separation means greater depth, but less resolution. The third factor is the frequency dependence on the penetration depth. As mentioned earlier, the higher the frequency, the more shallow the signal penetration into the soil. This frequency dependence can help determine the depth of a target. The greater the depth, the larger the target must be.

One effective method of obtaining an estimate of the maximum depth of penetration at a site is by using a technique called "forward modeling." Forward modeling uses the already known geological factors of the site and the theoretical response of the EMI system in a number of mathematical models to estimate the maximum depth of penetration and resolution.

Regardless of the depth of penetration, target resolution depends on the contrast of conductivity between the target and the surrounding soil. The larger the contrast, the more easily the target will be found. If the soil is highly conductive, it is possible that EMI methods could fail to identify an object buried within the conductive soil strata.

A time domain system might be better suited to locate objects in situations where the overburden masks a target since it is designed to be less sensitive to upper level conductivity. Upper level 
conductivity and nearby metal objects may make data readings appear unstable to the point of appearing random. This instability is referred to as "noise." Checking readings from additional surveys using different coil orientations might help to interpret the data and to eliminate the noise factor.

\subsection{Survey Techniques}

There are two common techniques used in ERMM surveying: profiling and sounding. Profiling involves taking readings at each measurement point along a survey grid using only a single frequency. $A$ single frequency determines the conductivity only for a specific depth. As measurements are made over the survey site, a total profile is taken of the subsurface conductivity at that particular depth. The most effective technique is continuous profiling. The EMI system uses a transmitter and receiver mounted on a mobile platform which is moved around the survey area while continuously taking measurements. This usually involves some type of data storage device such as magnetic tape. Continuous profiling is very common in airborne systems.

Sounding surveys use several measurements at each location. Each measurement is at a different frequency which has been calculated to yield measurements of conductivity at various depths. If the conductivity of the upper soil layers is higher than for lower layers, the survey results might be poor. However, for those cases in which the overburden is not a factor, a three-dimensional mapping of the subsurface showing the water table, the bedrock and its condition, and metallic objects may be possible.

Before conducting any EMI survey, it must determined whether the survey should be conducted from an aerial or a ground-based platform. The advantage of an aerial survey is its ability to cover large expanses of area and locate those places which need further (i.e., ground-based) investigation. Separate geographic sites within the range of one airfield can be incorporated into one contracted survey with additional transponder setups. While the costs for an aerial survey can be much higher than for a ground-based survey, they are fairly well established before the survey is contracted. Often omitted from ground surveys are the costs of safety requirements for ground personnel, access routes to the site and on site, and the clearing of foliage for survey grids. The site manager should ensure that these items are addressed in any cost estimate.

For ground-based surveys, several aspects of the site's topology must be considered before a survey can be performed. Typically, a transmitter is set up at a location and a grid is established to make the receiver coil measurements. At each grid mark, the receiver is set up, and the resultant electromagnetic field is measured. This represents a measurement of the conductivity of the subsurface between the transmitter and the receiver. Grid lines and spacings are dependent on the suspected target's size and depth. Spacings typically start at the maximum distance at which two readings from the same object may be obtained. After locating an area that requires a more detailed examination, more closely spaced grid lines are added to find the boundary of the source. The exact spacings of the grids, maximum resolvable depth, and the type of objects to be detected should be determined in the preplanning stage of a survey.

Another survey consideration is the artificial interference from man-made sources at the site. Metal objects such as chain link fences, rebar supports in concrete, and buried steel pipes or drums will give extremely strong readings. Power lines will also overload the receiver if they are too near the survey site.

When the survey data are presented, they will take some form which shows contours or areas of high conductivity readings. Often the shape of the anomaly will help indicate the type of target. For example, a pipe's anomaly is long and narrow, while a drum or a collection of drums has a much broader 
shape. (The data collected from these sources may be enhanced mathematically, or may be interpreted by a geophysicist.) Regions of very high, upper level conductivity will indicate areas in the site which cannot be completely mapped by EMI technology.

\subsection{Associated Technologies}

Electromagnetic inductive surveys are used to determine the location of sampling wells, hazardous waste plumes, and buried metallic drums. Furthermore, the boundaries of landfills and trenches can be found. However, the resolution of EMI methods for shallow objects is not as finely detailed as in other survey techniques. For shallow surveys, EMI methods are generally used to make a preliminary survey of an area, and another technique is used to examine areas of anomalous readings.

Active and passive EMI systems are usually employed with magnetometers to locate metallic objects. Similarly, ground penetrating radar (GPR) has been used in conjunction with EMI techniques. GPR was found to confirm EMI anomaly sources and investigate areas that were made unreadable by external interference (Cox, 1990).

\subsection{Questions to ask EMI Survey Contractors}

A. What type of system do you use?

Airborne systems are assumed to be active, frequency domain systems. The coil orientations, separation, and the frequency or frequencies being used might be questioned. For a ground-based system, any of several techniques might be appropriate for the survey site. Usually, DOE sites have an environmental geophysicist on staff who has made recommendations about the type of survey that should be conducted. It might be wise to also have the contractor make a recommendation about the proper technology and survey techniques.

B. What type of final output is produced?

To a large extent, this will depend on what type of target is being sought. If the survey is being used to find a specific object, such as a storage tank, then simply marking the area at the site or on a map might be sufficient. For general surveys or surveys in which the target might be the aquifer level over a large area, then a contour map might be more appropriate.

C. What types of objects can your system detect and at what depths?

Depending on site geology, EMI methods car best detect objects or volumes of soil with a high contrast in conductivity from the surrounding soil. Most often this would be a conductive target in a non-conductive surrounding soil. For conditions in which the target is in a normally conductive soil type, the results could be disappointing. In these cases, another survey technology might be needed. Either the site geophysicist or a contractor should be consulted about the usefulness of a survey technology for a specific survey area.

D. What are the costs?

For an airborne survey, the costs will be fixed and should vary only under unusual circumstances. For a ground-based survey, the costs will include items which are not usually thought of as being necessary for a survey. For example, the survey grid might traverse a section of dense foliage which would need to be cleared before the survey. The terrain might be more rough then expected, adding time to the survey. Any delay or difficulty in equipment setup might add time to the survey, thus increasing survey costs. 
E. What other technologies do you use to perform surveys?

Quite often, Magnetometry surveys are performed along with EMI surveys. In aerial surveys, the equipment is often installed in the same package as the EMI equipment. For ground-based surveys, Gravimetry or Ground Penetrating Radar surveys are often performed at the same time. 


\subsection{GRAVIMETRY SURVEYS}




\section{GRAVIMETRY SURVEYS}

\section{Synopsis}

Technology: Gravimetry

May Detect: Large-scale geologic structures

Large near-surface tunnels

Direction of contaminant migration

Landfill boundaries

Aquifer depth

Alluvial-bedrock interface

Salt domes

Underlying Principle: Large changes in subsurface density which alter nearby gravity field strength

Optimum Geophysical Conditions: Unlimited

\section{Extended Discussion}

\subsection{Introduction}

Gravimetry is the study of local variations of gravity and their causes. Gravimetry can be used to determine very large-scale geologic structures, large near-surface tunnels, and changes in subsurface soil density which might indicate the direction of contaminant migration or the boundaries of a landfill. For years, the oil and mineral exploration industries have used gravimetry to discover areas of possible deposits. Gravimetry technology was used in 1924 to help discover the Nash Dome oil deposit in Ft. Bend, Texas, possibly the first discovery of oil by any geophysical method (La Fehr, p.1634).

\subsection{Instrumentation}

Gravimetry can be used to find both the direction and strength of a gravity field at a specific point. Most often, however, the direction of the field is independently determined, and only the strength of the field is measured. There are many types of gravimeters, each with different applications and varying degrees of accuracy. The superconductive, free-fall, and pendulum gravimeters and their variations yield highly precise measurements but are not suited to portable applications. These gravimeters are absolute measurement devices; they measure the exact value of the gravitational field.

The gravimeters which are more suited to portable use are called relative measurement gravimeters, and they measure only the change in the gravity field strength from one position to another. Their advantages over the absolute measurement gravimeters are their lighter weight, more rugged construction, and faster speed of measurement. Though many types of portable gravimeters are available, there are two which are most commonly used: the spring gravimeter and the vibrating string gravimeter.

\subsubsection{Spring Gravimeter}

The spring gravimeter is the most common type of gravimeter used in portable applications. In the basic design, which is illustrated in Figure 2, a mass is attached to the free end of a lever arm. The 
mass is much heavier than the lever arm. The force of gravity acting on the mass will tend to swing the lever arm down, displacing it from a horizontal position. A counterspring is attached to the lever arm and to a solid mount on the gravimeter to partially counteract the effects of gravity on the mass-lever arm. The rest of the restoring force is supplied by a measuring spring which is attached to the lever arm and a calibrated measuring screw.

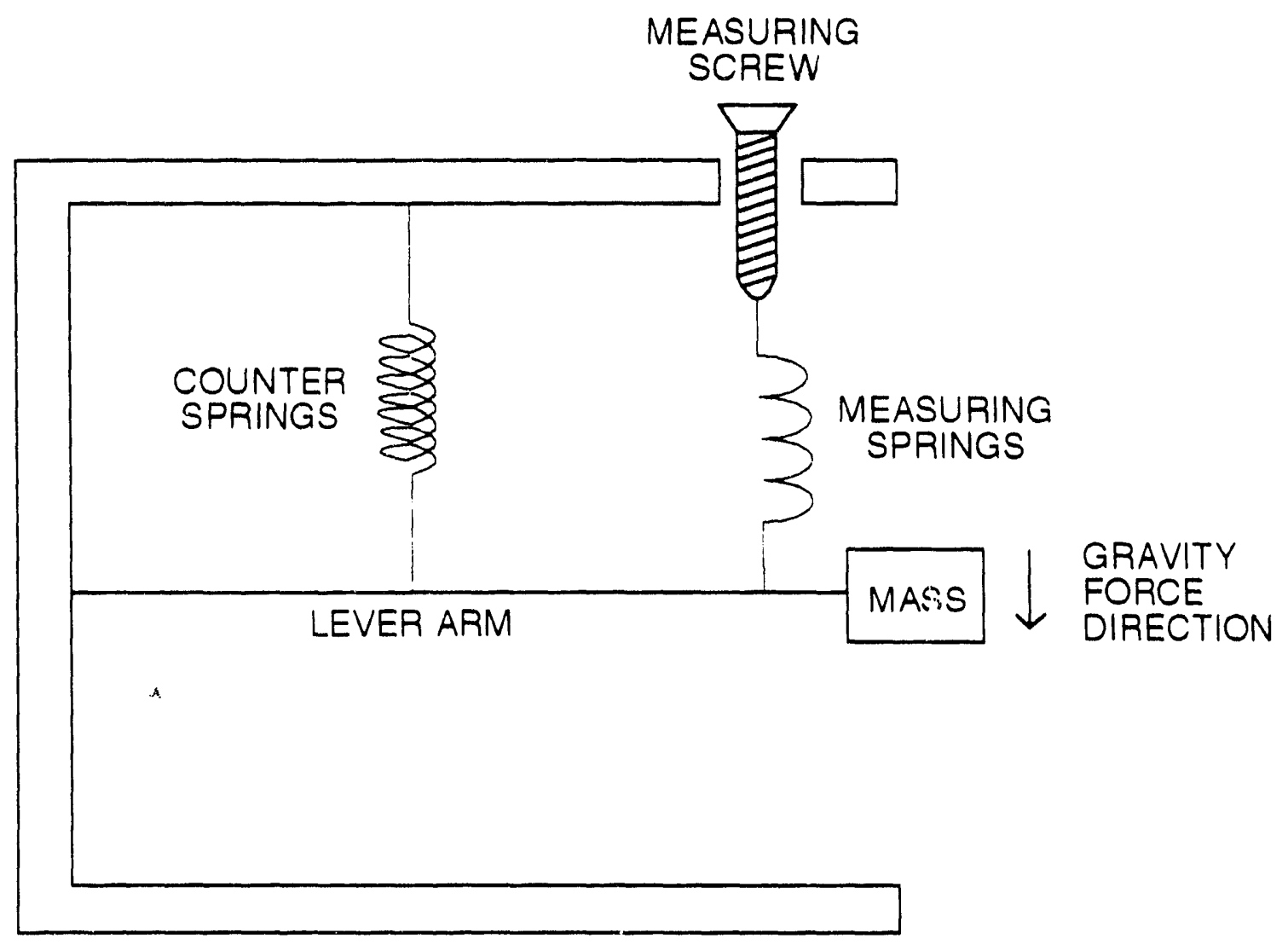

FIGURE 2. SIMPLE GRAVIMETER DESIGN

When the force of gravity and the tension supplied by the two springs are exactly equal, the lever arm will be horizontal. As the force of gravity weakens or strengthens, the mass will be displaced either up or down, respectively. At this point, the calibrated measuring screw will be twisted in or out, thereby adjusting the tension in the measuring spring. This is adjusted until the lever arm is again in the horizontal position. The measuring screw is calibrated ir, gravity measurement units so that the amount of adjustment necessary to rebalance the lever arm from one location to the next can be read. The deviation from the prior reading then can be determined and recorded in the proper gravity measurement units.

The gravimetry industry is fairly diverse, and manufacturers have made many modifications to this basic design. One of the most common modifications is to automate the adjustment of the measuring screw by electrostatic or electronic feedback systems.

\subsubsection{Vibrating String Gravimeter}

The vibrating string gravimeter uses a mass suspended on a string which is, in turn, fastened to a solid mount inside of the gravimeter. The force of gravity acting on the mass supplies a tension in the string. 
The string is then caused to vibrate, and the rate of vibration is carefully measured. The rate of vibration of the string is a function of the physical characteristics of the string (length, diameter, and material) and the string's tension. This is similar to the way a guitar string produces sound. Thicker strings are used for lower notes, and the pitch of a string can be adjusted by varying its tension. In a vibrating string gravimeter, the force of gravity acting on the mass will supply the tension in the string. A change in the force of gravity will cause a change in the tension of the string, thus causing a change in its rate of vibration. By noting the change in the rate of vibration of the string from one point to another, the relative change in the force of gravity can be calculated.

\subsection{Nature of the Measurements}

Every material object in the universe attracts every other object in the universe by a force which is directly proportional to the product of their respective masses and inversely proportional to the square of the distance between their respective centers of gravity. The center of gravity for a sphere is its geometric center. However, for a nonuniform density or irregularly shaped object, this point is determined statistically from the density distributions as seen from the point of measurement. This is usually offset from center and depends on the density distribution of the object.

A consequence of the force of gravity is the acceleration of gravity. When dealing with gravity measurements on the earth, the acceleration is normally referred to as " $g$." Thus, the force of gravity is proportional to the mass $\in S$ of the earth and the test object, but $g$ (acceleration) is proportional only to the mass of the earth and the distance of the test object from the gravitational center of the earth.

In gravimetry, $g$ is measured in units of centimeters per second per second $\left(\mathrm{cm} / \mathrm{s}^{2}\right)$ which are referred to as "gals." Some gravimeters (free-fall type) actually are measuring the acceleration of gravity, but most are measuring the force of gravity. However, the results are still expressed in terms of gals.

The earth's mass is the source of gravity which is of interest to gravimetry surveys; however, other factors (both internal and external to the earth) complicate its measurement. Corrections for these factors must be taken inth account during a gravimetry survey before actual values can be determined. Some of these complicating factors include: the earth's shape, the earth's rotation, the tidal effects, and the local topography.

\section{Survey Correction for the Earth's Shape}

The earth is not perfectly spherical in shape. It is slightly flattened at the poles and bulging at the equator. The difference is small (about 21 kilometers) compared with the magnitude of the radii involved (equatorial radius $=6,378$ kilometers, and polar radius $=6357$ kilometers), but the force of gravity at a point on the surface of the earth depends on its distance from the earth's center of gravity. Although this amounts to only a maximum of $0.34 \%$ difference in distance, precise gravimetry measurements can detect this difference. Thus, corrections of the raw survey data must include a factor for latitude.

In gravimetry surveys, the distance between the measuring device and the earth's center of gravity is the largest determining factor in the magnitude of the measurement. These differences in distance are called the local area's elevation. To help correlate actual gravity measurements to useful measurements, tw' 0 artificial surfaces have been devised to help in the analysis of gravity survey data: the reference spheroid and the geoid. Elevations are calculated from these reference surfaces.

The reference spheroid is the surface the earth would have if all the excess land mass were removed and the oceans were filled. It is an equipotential surface; that is, the force of gravity would be the same value and the gravity field would be directed perpendicularly down at all points on this surface. 
The second artificial surface is called the geoid. A geoid is defined in this manner: if canals were dug through all of the continental land masses and sea water were allowed to flow freely through them, the geoid is the sea level over the oceans and through these canals. Thus, the geoid is an equipotential surface which cuts straight through the middle of land masses.

Where the reference spheroid gives an equipotential surface on the assumption that there are no variations in the shape or density of the earth, the geoid takes these factors into account. The earth has a mean continental elevation of 500 meters and maximum elevations and depressions of around 9,000 meters, plus or minus, in reference to sea level. Obviously, the true sea level is influenced by these variations, and a survey must take these factors into account when making corrections for elevation. A geoid is a means of defining a practical mean sea level to help in these corrections.

The geoid and reference spheroid are not the same at all points. The geoid is warped upward under the continental masses due to the gravitational attraction of the material above it and is warped downward over the ocean basins. Figure 3 illustrates an exaggerated difference between the two.

\section{Survey Corrections for the Earth's Rotation}

To measure the earth's gravitational attraction, gravimeters measure the effect that the gravitational force has on a test mass: either how far it deflects a spring, how much tension it creates in a string, or some other effect. But gravity is not the only force acting on such a test mass. The largest such secondary force is the centrifugal force caused by the earth's rotation. Passengers in cars notice such a force when drivers make sharp turns at high speeds. Centrifugal force is the force which tends to push them into the car door. A lesser-known characteristic of the centrifugal force is that, for a constant rate of rotation, the further from the axis of rotation the stronger the force pushing radially outward. In gravimetry, the centrifugal force has its maximum effect at higher elevations near the equator and has zero effect at the poles (directly on the axis of rotation).

\section{Survey Corrections for Tidal Effects}

An additional factor that requires correction in gravimetry surveys is the tidal effect. As stated earlier, every object in the universe attracts every other object. The earth, moon, and sun are no exception to this rule. The sun and moon have the effect of slightly distorting the shape of the earth. While the earth's mantle shows very little deformation, the earth's oceans are noticeably affected. This has the effect of raising the local elevation and shifting the earth's center of gravity, a cyclic variation that can be measured at any point on the earth. Tidal effects cause large variations and require complex corrections in surveys.

\section{Survey Corrections for Local Topography}

Still another factor which requires a correction in gravimetry surveys is that of the local topography. The elevation of the measuring device affects its distance from the center of gravity which, in turn, affects the gravitational field strength. The gravimeter can be thought of as being situated on a flat plane which stretches out horizontally to infinity. Any mass which lies above this plane will tend to lessen the measured force of gravity due to the upward attraction of this mass. Thus, if the gravimeter were positioned at the base of a mountain, the measurement would be less than if the mountain were not there. 


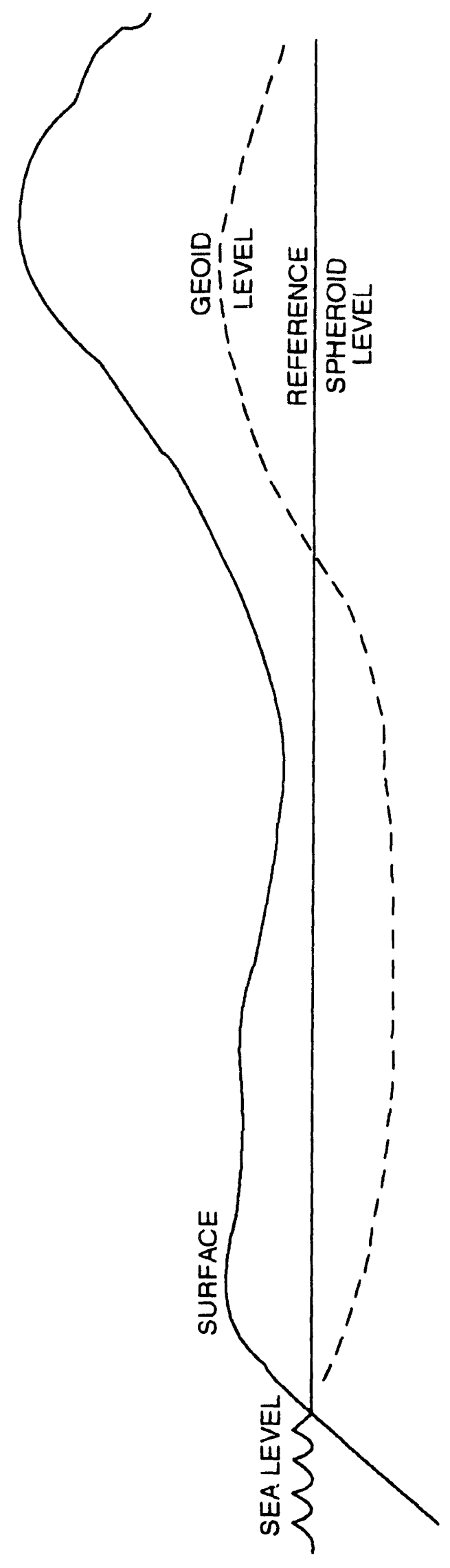

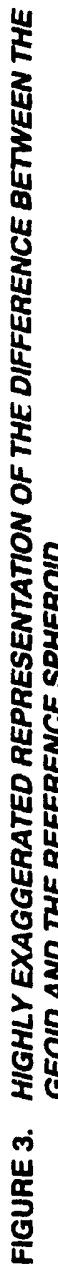


Corrections for these effects and a few others must be taken into account before the data from a gravimetric survey can be properly analyzed. Some of these corrections might be very small, but they are not trivial. The measurement for $g$ is in the order of $\$ 80$ gals, while differences in $g$ are measured in units of microgals or millionths of a gal. For extremely accurate surveys, even such factors as temperature, barometric pressure, and wind speed rnust also be accounted for due to their effect on the gravimeter itself.

\subsection{Target Type and Defectability}

When making gravity measurements, the distance between the gravimeter and the object causing the gravity field is very important because of the magnitude of the measurement. As discussed earlier, the strength of a gravity field decreases with distance from the object producing the field.

A second reason why the distance is so important is the way in which the strength of the gravity field varies when close to a very large object with varying density. When measuring the gravity field at a point, the gravimeter will measure the effects of all gravity-producing objects. These objects might be very large, but far away (like the sun and moon), or they might be volumes of differing density within the earth. Close deposits of dense material will produce greater iocalized gravity field strength differences than would a homogenous !ayer of soil.

As the distance from the earth increases, these variations in the gravity field tend to average. This makes the effect of far away objects like the moon and sun appear as if all of their mass were concentrated at their respective centers of gravity. However, when near a large object of varying density, these differences can be detected with precise measurements.

A consequence of the effect of the gravity field strength averaging with distance is that, as the height at which a measurement is made above the earth increases, variances are measurable only with increasingly larger volumes of aiffering density (salt domes and deep ocean trenches). For this reason, it is doubtful that airborne surveys could be adapted to the finely detailed work required in Environmental Restoration/Waste Management (ER/WM) work.

No gravimetric survey, with typically achieved field results, can directly detect subsurface pollutants or buried drums. However, there are some detectable objects or conditions which might be useful for ERMiM work, and land-based gravimetry appears to be best adapted to this type of work. There are two types of land-based gravimetric surveys performed: classical gravimetry and gradient gravimetry. In classical gravimetry, measurements are made at separate locations, and the relative differences are recorded and compared. Subsurface geologic conditions can then be determined from this data after the survey corrections are made. When extremely precise measurements are taken in such a survey, it is sometimes referred to as a microgravity survey.

In gradient surveys, two gravity measurements are made with one made at a known vertical distance above the other. This type of survey measures the rate at which the strengih of the gravity field is changing (known as the gravity gradient). For a sphere of uniform density or layers of uniform density (as the earth is assumed to be for simple calculations), the gravity measurement taken at the surface would be the same as if all of the mass of the sphere were located at the sphere's center. For a uniform density earth, a measurement made at the equator on the surface would be the same as measuring a small object of the same mass at a distance of 6,378 kilometers. A displacement of three meters would cause only a slight difference in the measurement; however, for an object buried at a depth of three meters, the difference caused by an additional three-meter displacement would cause the measurement from this object to decrease to one-fourth of the lower reading.

By making a survey arid noting where the measured gradient differs from the theoretically calculated gradient, some determinations can be made concerning subsurfac e structures. Dr. Z. Fajklewicz of 
the Geophysical Prospecting Co. in Warsaw, Poland, reported some success using this method in finding abandoned mining tunnels at a depth of 15 meters (Fajklewicz, p.1016).

Most surveys related to prospecting which might be applied to the ERMM field are microgravity surveys. In these surveys, precise differences in measurements are calculated between different survey points. Using this method and limited ground truthing, some success has been reported in ERMMtype projects. For example, it is quite common for a gravimetry survey to determine the alluvial-bedrock interface or the depth to the local aquifer. This gives an indication of how pollutants could migrate to the local aquifer.

Both of these survey types can be performed from an aerial platform, but the ability to detect small subsurface targets is greatly diminished for two significant reasons. First, as stated earlier, with distance, variations in the gravitational field tend to average together. Thus, with increased altitude, the size required for an object to be detectable increases dramatically.

The second reason is the effect of the aircraft's motion on the gravimeter. No aircraft travels in perfectly level flight. There is the vibration caused by the engine(s), the pitch, yaw, altitude changes, and weather conditions that even the most experienced pilot can not avoid. Many instruments have been designed to compensate for these motions, but all have the effect of decreasing the sensitivity of the instrument. The resolving power of a gravimeter is related to aircraft motion. For a land-based survey, the gravity field is determined at a single point, but it takes a gravimeter from several seconds to a few minutes to make this measurement. With a gravimeter mounted on a helicopter traveling at 40 meters per second, it is possible that a single gravity reading might be the integrated value of the gravity measurement for the distance of over a full kilometer.

\subsection{Survey Techniques}

Typical surveys are laid out in a grid-type geometry, where the local topography allows. Grid spacing is determined by such factors as target type, gravimeter sensitivity, and local topography; for detailed survey work, a spacing of 50 to 100 feet is common. Because elevation affects the readings to a large degree, it is necessary to know the elevation to an accuracy of one foot. Thus, an extremely accurate topographical mapping of the survey area is necessary. The mapping should include an area beyond the boundaries of the survey area because of the effect that large nearby mountain ranges or valleys have on the gravity measurements.

Readings of a survey area might still contain errors, no matter how carefully the readings are taken. All gravimeters, with few exceptions, have some sort of drift in their readings because gravimeters are bounced around during relocation. The bouncing of the mass on the spring causes the spring to stretch slightly. By regularly making check measurements at a base location, a tension curve can be determined. Using this curve, data can be corrected to the level of accuracy that an invariant gravimeter would have read during the survey. If, however, the gravimeter were jarred or received a large bump that caused a big variation at some point, then the entire survey might have to be redone.

The most important part of the gravimetry survey is accomplished after all the data readings are taken. At this point, all of the corrections are made to reduce the data into meaningful values. These values are then used to determine what, if any, geologic structures might be present. There are many techniques available which give meaningful results, but none are perfect. There is one common phrase in the literature deccribing interpretation techniques: "There is no unique solution to the gravimetry modeling probler..." This means that for any set of data, there is usually more than one set of conditions which could lead to these data. However, a good geoscientist with some knowledge of the survey area (and perhaps the assistance of some complementary surveys) should be able to make an accurate model of the subsurface enviranment. 


\subsection{Associated Technologies}

Gravimetry is capable of finding subsurface tunnels or caverns, sink holes, and some geologic structures. The nature of some of these geologic structures can be used to indicate aquifer levels or the direction and speed of some pollution migration. But, no results can be relied on with $100 \%$ confidence without some independent testing such as taking subsurface soil samples. This will indicate the soil's characteristics (density, porosity, and grain size). Another such test is a seismic survey. This will indicate fractures in the bedrock, aquifer levels, and subsurface strata structure. Both of these techniques are, however, very expensive for large-area characterization. Quite often, a magnitometry survey is conducted with a gravimetry survey. Some of the results from a magnitometry survey will indicate a geologic condition that will help clarify a gravimetry survey's results.

\subsection{Questions to ask Survey Contractors}

A. What types of objects or geologic conditions are detectable with your system?

The "system" would refer to both the hardware and the data reduction/mapping software. The sensitivity of the instrumentation is important, but an inadequate software package could negate the benefits of a more accurate instrumentation package. One software package compares corrected field data and a software geologic model supplied by a geophysicist knowledgeable in the local geology. It indicates a correlation between the calculated data that the model would produce and the corrected data. A low correlation in some area indicates that changes need to be made in that area of the model and another iteration of the calculations is made. When the correlation rate is sufficiently high, the model is declared a "good fit." However, there are still many subsurface structures which could go undetected. For the finely detailed results needed in ERMM work, these limitations must be known.

B. What type of final output is produced?

Some contractors produce a subsurface relief map; others produce different outputs. Pernaps the contractor could modify the output to a form more useful to the specific ERMWM problem at hand.

C. What type of topographical survey is performed along with the gravimetry survey?

For precise data recordings, positions and elevations of measurement locations must to made to an accuracy of 0.3 meters or better, depending on the survey conditions. This is usually performed in a gravimetry survey by first surveying a location by traditional topographical means, and then making the gravity measurement. For an aerial survey, positioning equipment such as microwave positioning, lidar altimeters, and other accurate equipment is used.

D. What other survey techniques can you perform?

Gravimetry alone may not give sufficient information about an area to make a proper decision for an ERMWM problem. Some contractors also perform surveys such as magnetometry or seismic surveys, which might be performed along with gravimetry to give a higher degree of confidence in the final results.

E. What are the costs?

Under the best of conditions, a topographical survey team can make readings at , perhaps, 30 to 50 locations in a single day. The survey area size, grid spacing, and terrain conditions will, thus, affect the costs of labor and equipment rental. Processing costs also vary according to special characteristics of the survey and the contractor. 


\subsection{GROUND-PENETRATING RADAR SURVEYS}




\section{GROUND-PENETRATING RADAR SURVEYS}

\section{Synopsis}

Technology: Ground-Penetrating Radar

May Detect: Metal objects

Hydrocarbon plumes

Depth to the water table

Some subsurface geologic features

Underlying Principle: Transmitted electromagnetic pulses aimed at a target area and reflected back as an echo from a metallic object

Optimum Geologic Conditions: Dry, sandy, nonconductive soils

\section{Extended Discussion}

\subsection{Introduction}

Using Ground-Penetrating Radar (GPR), a survey team can fully map a subsurface environment. GPR can be used to find metal objects, hydrocarbon plumes, the depth to the water table, and some geologic features of the subsurface soil strata. When soils are conductive (when they are wet or have a high clay content), the depth of penetration can be less than one meter. However, in nonconductive soil conditions (dry sandy soils), the depth of penetration can be as much as 50 meters with resolutions superior to any other subsurface geophysical survey technique.

\subsection{Instrumentation}

GPR systems are similar to other radar systems. First, an electromagnetic pulse (EMP) of energy is emitted from a transmitting antenna. The EMP then travels vertically downward until it strikes a target, and a portion of the energy of the EMP is reflected back. This is referred to as an echo, and a great deal of information can be extrapolated from the characteristics of the echo. The echo is, in turn, detected by the receiving antenna. The target is a boundary between two media of differing dielectric constants (electrical characteristics). The boundary can be an interface between two layers of different soil types, an interface between metal and soil or air, or the interface between water and another material.

\subsubsection{Antenna Configuration}

The critical component in all GPR systems is the antenna configuration. Many systems (especially ground-based systems) have two antennas, a transmitter, and a receiver. This is called a bistatic configuration. The extra antenna compensates for a lack of propagation distance between the antenna and the target. For a ground-based system, the antennas are in physical contact with the ground itself.

The EMP width is referred to in units of time duration of the pulse because in various types of soil, the EMP travels at different velocities, and the physical dimension of the pulse varies. For a GPR system, 
pulse durations of 10 nanoseconds (ns) are not uncommon. The physical duration of such a pulse varies from one soil type to another, but a propagation velocity of 0.1 meters per nanosecond is typical. For a target buried one-half meter beneath the surface, it would take the EMP 5 ns to reach the target. It would take the echo another 5 ns to return to the antenna.

If the target were buried nearer to the surface or the propagation velocity were a little faster, then the echo might return to the antenna before the antenna had completed transmitting the pulse. Use of a second antenna to receive the echo allows the detection of an echo from a target which is very near the transmitting antenna.

For airborne systems, buried targets are many meters below the antenna. In this case, there is sufficient time for the system to transmit a full duration EMP and switch the single antenna to a "receive" configuration before any echoes can be returned.

Not all of the energy of the echo returns to the receiving antenna. Most of the energy will bounce in such a direction that it will never be detected. If, however, the echo has multiple bounces or if a portion of the transmitted EMP travels in an undesired direction, then a false return could be detected. Antennas have a radiation pattern which focuses most of their energy in a specific direction. However, aii antennas radiate some energy to the sides (side lobes) and even directly backwards.

In a GPR survey, all returns are assumed to indicate a target which lies below the GPR antennas. If the antenna were under a metal bridge or very near a metal building, then a false return could indicate a subsurface target which actually lies above or beside the radar unit. To compensate for this, some antennas (both transmitting and receiving) are shielded to block any echoes from undesired directions.

\subsubsection{Pulse/Echo Techniques}

Though all GPR systems operate according to the pulse/echo principle, there are significant differences between them. One difference is the way in which a system transmits a pulse. If electromagnetic energy is being continuously radiated, then the system is called a continuous emission radar. If electromagnetic energy is being radiated in discrete pulses, then the system is referred to as an impulse radar. The impulse radar is the most commonly used system and is known by several names: Subsurface Imaging Radar (SIR), ground-probing radar, or ground-pulsed radar.

The detectability of any echo depends on its strength. Both the power output and beam width of the transmitting antenna affect the return echo strength. All antennas radiate an EMP in a pattern which spreads with distance, and the angular extent of this spread is called the antenna's beam width. Most radars have a very small beam width; sometimes a spread of less than one degree is achieved. For GPR, the beam widths are quite a bit larger, sometimes as large as $90^{\circ}$.

When a GPR antenna emits an EMP, the pulse will spread as it penetrates deeper into the subsurface, forming a cone-shaped radiation pattern. As the pulse penetrates deeper into the soil, its energy concentration becomes more diffused; therefore, the amount of energy in the portion of the pulse which strikes the target will be less for targets of the same size which are buried at deeper depths. There are two other characteristics of the EMP subsurface transmission to consider. Some of the energy of the EMP is absorbed as it travels through the soil, and the echo increases its beam width as it travels back toward the receiver. All three of these factors combine to limit the depth of detectability for a GPR system. To compensate for this, surveys use sensitive receiving antennas which can detect extremely weak echoes; however, they are also very sensitive to electrical noise generated by local factors such as nearby radio transmitters or metal buildings. 
For an airborne system, the antennas are designed to give as little spread as possible, but they do not have a narrow beam width. The area of the ground surface over which the transmitted EMP is spread is referred to as its "footprint." The size of the footprint depends on the antenna's beam width and the height at which the aircraft is flown. More energy is transferred into the subsurface surveyed area with a smaller footprint. To keep the footprint as small as possible, air-based systems are flown close to the ground, usually at an altitude of 50-300 feet, where safety and local conditions allow. Losses due to a greater distance between the radar antenna and the target are compensated for by a greater power output of airborne radar systems.

\subsubsection{Output}

The output of a GPR survey can take several forms. In one type of survey, the echo returns can be viewed in real time on a video screen as the survey is being conducted. This has the advantage of being able to immediately redirect a more careful or detailed search over an area where some anomalous result was seen. Other outputs are the result of the processing software used on the survey data which can highlight targets by using a number of filtering techniques. The output could be a colorized printout, wiggle traces, or other specialized formats.

\subsection{Nature of the Measurements}

The results of a GPR survey are determined by measuring the characteristics of the return echo. The time delay between the transmitted pulse and the return echo indicates the depth of a target, and the strength of the return indicates characteristics about the type of target. As stated earlier, the strength of the echo for any target partially depends on the amount of energy in the EMP striking it. In many respects, this is a function of the power output of the survey system; however, there are other considerations.

An EMP traverses through a medium until it reaches an interface with another medium of differing electrical characteristics. At this interface, some of the energy o? the EMP is reflected, and some of the energy passes through. At the first interface, the strength of the return should be fairly high since most of the EMP energy is reflected. When the next interface is reached, the energy of the EMP is less, so the return from this interface will be weaker. At successively lower interfaces, the return echo becomes too weak to be detected by the receiving antenna.

Some of the energy is absorbed by the material through which the EMP travels, which is referred to as attenuation of the pulse. Attenuation is measured in units of $\mathrm{dB}$ (a logarithmic measure of the ratio of the input power to the output power) per meter. $A 6-\mathrm{dB} / \mathrm{m}$ attenuation means that one half of the power measured at the surface is available at a subsurface distance of one meter. If the EMP is not fully reflected, then the echo's energy is still smaller, and the echo is again attenuated as it returns to the surface. Fortunately, not all soils have a very high attenuation factor or GPR would have very limited applications.

The characteristics of the transmitting antenna can be designed to compensate for attenuation of the soil by emitting the maximum amount of energy from the transmitting antenna into the first medium through which the pulse must travel. The maximum amount of power will be transmitted if the electrical properties of the antenna and this first medium are the same.

For an airborne system, the first medium would be the air. The EMP then travels until it reaches the ground where there is a strong difference in the electrical properties between the two mediums (air/ ground), and a large portion of the EMP's energy is reflected back. Thus, for an airborne system, the 
ground provides the strongest return. This can be useful in some cases. For example, when there is a thick grass cover, depressions can be easily found.

For a ground-based system, the antenna is in direct contact with the ground and should be closely matched to the soil's electrical characteristics. Though various soil types have differing electrical characteristics, a proper choice of antenna design can provide a significant improvement in the amount of energy which is directed to subsurface targets by a ground-based unit.

Two major electrical characteristics of the soil, which are important in determining the reflectivity of an interface and the attenuation of the soil, are the soil's dielectric constant and the soil's conductivity. The larger the difference between the dielectric constants of two mediums, the better the reflectance; the greater the conductance of the soil, the larger the attenuation.

A soil's conductance is a measure of the its ability to conduct electrical current when there is a voltage potential difference between two points in the soil. The larger the conductance, the better the ability to conduct current. The EMP is composed of a rapidly varying voltage signal. As the EMP passes through the soil, there is a temporary difference in the voltage potential between different points in the soil, and a current is formed which absorbs energy from the EMP. The better the conductance, the more current; the more current, the more energy absorbed; and the longer the distance the EMP travels through this soil, the more energy is absorbed. Again, the measure of the amount of energy lost in a signal per its distance is its attenuation factor. Salt water, soils with heavy ore content, and "clayey" soils are very conductive, so the EMP is highly attenuated in such soil conditions.

The dielectric constant has two effects on the EMP. First, the velocity of the EMP through a material is an inverse function of the dielectric constant. The higher the dielectric constant, the slower the velocity. The second effect is a more fully reflected EMP at an interface between two mediums of highly differing dielectric constants. Metals are the best reflectors, interfaced with anything. Combinations such as hydrocarbons (with a low dielectric constant) floating on water (with a high dielectric constant) also offer a highly reflective interface. It is important to have sharp contrast between the two mediums. For instance, if the hydrocarbons and the water were mixed or both diffused into the surrounding soil so that there were no sharp interface, then the concentration of hydrocarbons might go undetected.

A target's depth, as indicated by GPR, depends on the assumed value of the dielectric constant of the soil. The output of GPR is graphed along two axes. The horizontal axis indicates the distance along the surface over which the survey was taken. The vertical axis indicates the time it takes a for a pulse to travel through the soil to a target and be reflected back. The deeper the target, the more time taken. If the soil is uniform, then the vertical axis is linear. A target's echo which took twice as long to return would indicate that the target is twice as deep.

Since soil is composed of various strata of differing soil types, a soil's dielectric constant can change, and thus the depth versus time relationship in the output graph might not be linear. For this reason, the output graph of a survey must be assumed to be an indication of relative depth and not a calibrated distance. When returning to an area for remediation procedures, the output of a GPR survey may indicate a target at a slightly greater or lesser depth then it might actually be.

The resolution between two objects is also a function of the soil's dielectric constant. As with most radars, the pulse width determines the resolution. Resolutions to one-half of a pulse width are possible. Though this value differs from location to location, current ground-based systems claim resolution capabilities of between 10 centimeters and 1.5 meters with a depth of detectability of up to 50 meters (under perfect conditions). Airborne systems claim resolutions of 20 centimeters with a depth of detectability of 20 meters.

Results can sometimes be misleading in a GPR survey. If an antenna is unshielded, the return echo might be from a direction other than below the antenna. If the antenna becomes tilted (for example, if 
the antenna were dragged over a small knoll), then the primary look direction might not be directly beneath the antenna. In addition, if a sufficient amount of surface material is very conductive, then lower targets might be masked. When there are conditions of rough terrain (under metal bridges or where a large amount of surface debris exists) a GPR survey might be unadvisable.

\subsection{Target Type and Detectability}

GPR can be used to find metal objects (steel drums, storage tanks, utility cables, etc.), trench and landfill boundaries, certain geologic structures, and (under proper conditions) the extent of a hydrocarbon plume or the depth to the water table. Metal targets are very reflective and are easiest to detect in a GPR survey.

The GPR measures the EMP echo from an interface of two media with differing dielectric constants. Hydrocarbons floating on water form a good reflector due to the differing dielectric constants of water and the hydrocarbons. Water pooled in certain soil types will also be a good reflector; however, if the interface between the water and the soil or the hydrocarbons is not sharp, it is possible that such a mixed interface might not be detected.

Compacted soil has different electrical properties than loose soil. Loose soil has a greater porosity. Porous rock structures can fill with air, water, or loose soil, and this is referred to as a fracture. The interface between loose and compacted soil as well as the fractures in rocky structures are reflective. The output of a GPR survey can clearly show the boundaries of a landfill, the location of different soil strata, or the position of fractures in the underlying bedrock. This kind of data helps to determine the extent of a polluted area and the direction in which the pollutants might migrate.

Current ground-based GPR systems claim resolutions between 10 centimeters and 1.5 meters with a detectability depth of up to 50 meters under perfect conditions. For airborne systems, possible resolutions of 20 centimeters with a detectability depth of 20 meters are claimed. However, not all areas have a penetration depth that is this high. For example, in southern Nevada, attenuations of $18 \mathrm{~dB} / \mathrm{m}$ are common because of a heavy clay concentration in the soil. This means that at a depth of one meter, the EMP will have one-eighth of the power that it had at the surface. For a fully reflected echo from a target buried one meter below the surface (two-meter travel distance), the strength of the return echo will be one-sixty fourth of the transmitted energy. Thus, southern Nevada is not a good area for GPR surveys. However, areas with dry sandy soils are appropriate for a GPR survey.

\subsection{Survey Techniques}

The type of survey performed depends on the kind of platform being used and the target being sought. GPR systems mounted on aircrait are limited to searching an area according to a well defined search grid. Careful attention should be paid to aircraft position and altitude measurements during the flight because GPR systems record data so fast that it can be considered a continuous measurement method. If proper position records are not kept, then the location of an anomalous GPR reading might be difficult (if not impossible) to find. Quite often, the GPR system is set up with a video camera viewing the radar's footprint pattern on the ground. Then the surface area above an anomalous section of the output can be more easily found.

Generally, ground-based GPR systems have more flexibility in survey techniques because of the two antennas used with most systems. A general search for any target would best be performed by setting up a search grid and surveying along this pattern. As with air-based surveys, careful attention should be given to the position of the GPR system during a survey in order to relocate any areas of anomalous readings. 
Sometimes obstructions, such as walls or shrubbery, may block a portion of a survey area. If the GPR system being used has a detachable receiving antenna, then the surface below these obstacles can still be surveyed. As previously mentioned, the transmitting antenna radiates the EMP in a wide angular pattern. As the EMP strikes an object at an angle which is not directly below the transmitting antenna (angle of incidence), it will produce an echo return which travels back toward the surface at an angle (angle of reflection) which is equal to the angle of incidence, but directed away from the transmitting antenna (Figure 4). If the transmitting antenna and the receiving antenna were placed on opposite sides of a barrier, then the subsurface below the barrier could still be surveyed.

Another survey technique is the common depth point procedure. In this procedure, the antennas are placed side by side over the target and then moved away from each other at a constant rate of speed. By using the target as a known reference point in all of the measurements and at different antenna positions, several propagation distances can be determined for the EMP/echo. By observing how the EMP/echo propagation timing varies, some determination of echo velocity can be made. With some knowledge of the soil type, this method has been used to determine how the moisture content of the soil varies with depth, as well as the depth of the water table in sandy soils (Fenner and Smith, 1991).

The timing of a survey is as important as the survey method used. Saturated soils are more conductive then dry soils. If there are salts present in the soil, adding water will greatly increase the soil's conductivity and its attenuation factor. Surveys conducted following a rain storm should allow sufficient time for the soil to dry.

Fresh water is relatively nonconductive, so it is possible to obtain good surveys over a lake. Areas that are usually wet are conductive because of the interaction of water and soil. These areas can be better surveyed if the survey is performed when the area is frozen and the water reacts less with the soil. A common way to survey the bottom of a shallow lake is to survey the top of the lake when it has a safe, thick layer of ice. Then the ice acts as a platform for the antennas, and the EMP propagates well to the lake bottom below.

\subsection{Associated Technologies}

GPR can be used to detect metals, geologic structures, and soil changes in density, type, and moisture content. Sometimes, however, conditions exist under which other survey technologies, such as magnetometry or electromagnetic inductive survey methods, should be used to find metals. Magnetometry is limited to finding only iron-based objects and is limited in its detectability depth.

Electromagnetic inductive survey methods can be used to find metal of all kinds, but the resolution of this method is very coarse compared to magnetometry or GPR techniques. Raw GPR data graphs are very easy to interpret, and magnetometry data are only slightly more difficult for simple targets. Electromagnetic inductive data require significant processing to be interpreted.

Soil strata, geologic structures, and fractures in bedrock can be found using seismic methods which are strictly ground-based. Seismic survey methods are very expensive and have a more coarse resolution then GPR, but their detectability depth extends many hundreds of meters.

It should be noted that GPR is usually not the first method used in a survey. In most surveys, the primary technology is one that covers a large area in a small amount of time. If an anomaly is found in the data, then a more careful search is employed using a method which gives more detailed results. When a GPR survey is appropriate, the first search is often conducted with electromagnetic inductive methods. After any anomalous areas are found, then another survey technology (like GPR) with a finer resolution capability is used. 


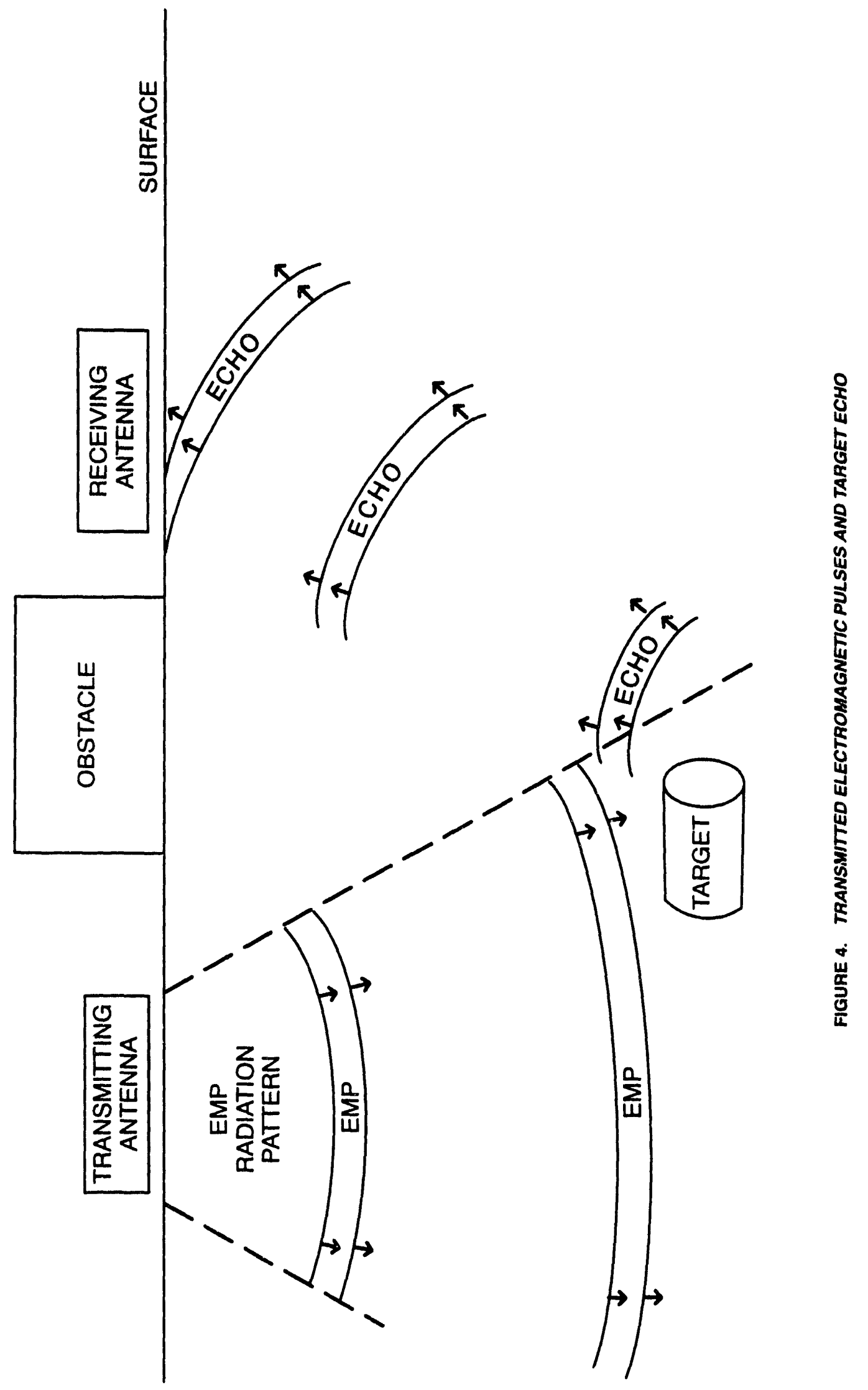




\subsection{Questions to ask Survey Contractors}

A. What are the depth and resolution capabilities of your system?

To answer this question, the contractor must have some information about the geologic and soil conditions of the site. For certain areas, such as areas with wet or "clayey" soils, GPR simply will not work. For airborne surveys, geophysicists who are knowledgeable about GPR requirements should examine the area.

B. What type of system is being used?

There are various survey systems available. For a ground-based system, are the two antennas separable? Different ways of moving the two antennas are possible; hand dragging the system or towing the system behind a small tractor is possible. This might provide some exploration techniques not possible with other systems.

C. What items are included in the survey costs?

Costs for a survey include: mobilization and location costs, survey costs, and processing fees. Since there are many ground-based survey contractors throughout the country, mobilization and location costs should be minimized when local contractors are used. For airborne systems, the cost of the survey could include an additional aircraft rental fee, depending on the survey contractor. Always ask the contractor about any special licensing or processing fees.

D. Are there any survey technologies available which might yield better results than GPR?

It is possible that another survey technique might yield faster results in a first-time survey of a large area. Then GPR could be used to more carefully examine an area which produced anomalous readings.

E. What type of output is produced?

Several different processing techniques give outputs which are generalizations of a seismic wiggle trace plot. False coloring and statistical filtering of the data provide a look at the subsurface as if it were sliced open along the survey line. Other techniques can produce a three-dimensional model of what the entire subsurface area might look like. 


\subsection{MAGNETOMETRY SURVEYS}




\section{MAGNETOMETRY SURVEYS}

\section{Synopsis}

Technology: Magnetometry

May Detect: Metal drums

Steel or iron pipes

Well casings

Holding tanks

Objects made of magnetic material

Some types of landfills

Hydrocarbon plumes

Underlying principle: Locating magnetic and iron-based objects which alter the earth's magnetic field

Optimum Geologic Conditions: Any kind of soil with non-magnetic characteristics

\section{Extended Discussion}

\subsection{Introduction}

Magnetometry, the study of magnetic fields, is used in surveys to remotely sense objects which alter the earth's magnetic fields (magnetic materials, some landfills, and some hydrocarbon-saturated soils) (Henderson, 1984). There are two magnetometry survey techniques: the total field technique and the gradient technique. The total field technique measures the total magnitude of the earth's magnetic field (due to all sources) at a certain point. The gradient technique employs two magnetometers, and a stronger reading on one magnetometer indicates a nearby object with strong magnetic qualities. The survey and data analysis techniques are the same for both types of surveys. However, total field surveys are the most commonly used.

\subsection{Instrumentation}

The measuring device used in magnetometry is called a magnetometer, and there are several types: the flux gate, the dip needle, and the proton precession. Currently, the most commonly used magnetometer is the proton precession magnetometer (PPM) which uses the physical characteristics of spinning protons to measure a magnetic field. When any spinning object is subjected to an external field which is not directed along the object's axis of spin, the object will begin to rotate around an axis parallel to the external field, similar to the way a top will begin to wobble in the earth's gravitational field. This wobble is called "precession," and the rate of precession is directly related to the strength of the applied field.

A proton precession magnetometer is based on this same principle. A sample of hydrogen-rich liquid such as water, kerosene, or alcohol is surrounded by a large coil of wire. Hydrocarbon fluids are used because the spinning protons (or hydrogen nuclei) behave like small spinning magnetic dipoles. When a current is applied to the surrounding coil of wire, a large induced magnetic field is set up within the sample. The induced magnetic field is much greater than the earth's magnetic field, so the 
magnetic dipoles of the spinning protons will align themselves with the field direction of the coil of wire. When the current in the coil is stopped, the induced magnetic fieid of the coil of wire also stops. The spinning protons will then begin to precess at sut an axis parallel to the direction of the earth's magnetic field.

The earth's magnetic field is relatively weak, and the normal molecular interactions of the fluid will eventually cause the magnetic dipoles of the nuclei of the hydrocarbon sample to become randomly orientated. For a short time, however, the protons will be spinning at a uniformly precessional rate inside of the coil of wire. These spinning magnetic dipoles, in turn, induce a small current in the coil of wire at a frequency which is directly proportional to the strength of the earth's magnetic field at that point. The direction of the induced magnetic fieid is unimportant as long as the fields of the earth and the field produced by the wire coil are not parallel.

The induced current is in the range of a few micro-amps with a frequency of approximately $2,000 \mathrm{~Hz}$. Precise measurements must be made by measuring total field intensity to an accuracy of a few gammas (one gamm 3 equals one nano-tesla). Some models can measure to an accuracy of a few tenths of i gamma.

\subsection{Nature of the Measurements}

\subsubsection{Effects of Magnetic Fields}

T.le earth's magnetic field can be thought of as being analogous to a large-br,r magnet buried "within the earth. One way of describing a magnetic field graphically is by using "flux lines." These imaginary lines emanate from the ends (poles) of the magnet and follow the direction of the field at any point. A stronger field is indicated by a heavier concentration of flux lines in that area. Figure 5 is a simplified representation of the earth's magnetic field. The flux lines emanate from the magnetic poles of the earth in a direction perpendicular to the surface and are relatively concenirated. Near the magnetic equatorial region, the flux lines are spread out and are nearly parallel to the surface. In reality, at the earth's magnetic poles, the field is directed perpendicularly to the surface at a strength of approximately 60,000 gammas. At the magnetic equatorial region, the field is generally parallel to the surface at a strength of 30,000 gammas.

Because targets or anomilies are detected by variations in the total magnetic field, it becomes necessary to understand the rrocesses which cause these variations. One characteristic of the total magnetic field is the strength of the field, but for a multi-source characterization, the direction of the field is also important. In mathematics, anything which is described in terms of magnitude and direction is described graphically in terms of vectors. While the direction of the field is of little concern, the way vectors are added is important (Figure 6).

A field is represented by a long arrow. The direction of the field is represented by the direction of the arrow or vector. The strength of the field is represented by the length of the vector: the longer the vector, the stronger the field.

Vectors are added by placing the tail of a second vector on the point of the first vector while maintaining the proper direction. A third vector is then drawn from the tail of the first vector to the point of the second vector. This resultant vector indicates the tota' field strength and direction at that point. Thus, even if a target source were fairly large, if the field it produced were orientated the wrong way, the size of the anomaly it produced could be misleadingly small.

In addition to the earth's magnetic field, there are also magnetic fields caused by a high content of magnetic minerals, such as magnetite, in some soils. Therefore, some knowledge of site geology is 
helpful before a survey is conducted. High magnetite content in some soils can cause enough "noise" in a survey so that some weaker targets may go undetected.

Any random fluctuations in the recorded data caused by sources other than those targeted during the survey can be considered as noise. Cultural noise is caused by any object or electric field which might interfele with the measurement of anomalies produced by the target of concern. Nearby fences, utility lines, water pi,as, rebar in concrete, or radio transmitters are considered sources of cultural noise. Additional noise may be caused by the effects of solar activity in the earth's ionosphere and the earth's magnetosphere.

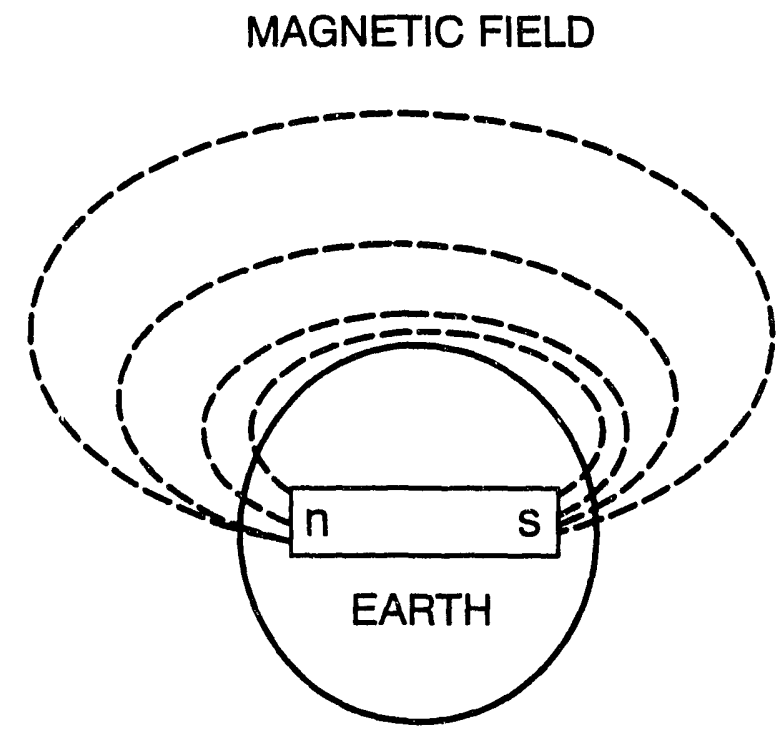

FIGURE 5. REPRESENTATION OF EARTH'S MAGNETIC FIELD

VECTOR ADDITION

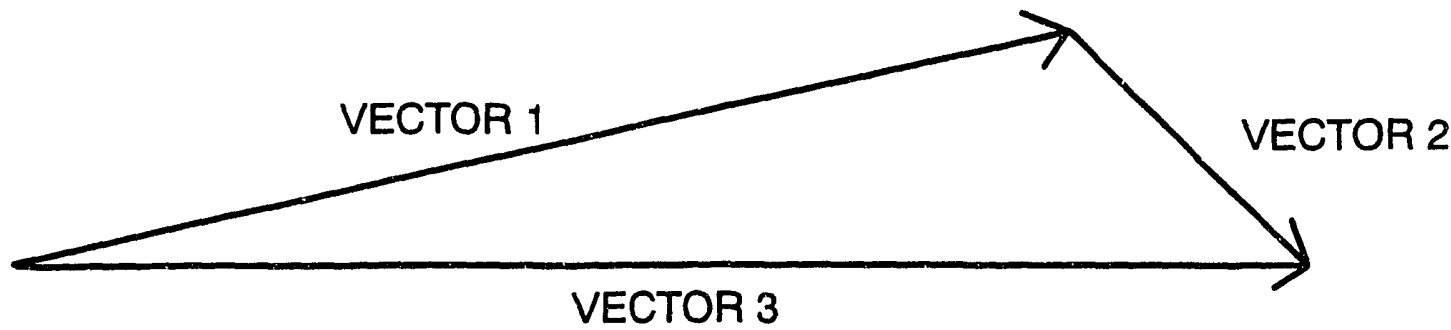

RESULTANT VECTOR

FIGURE 6. VECTORS CHARACTERIZING A MAGNETIC FIELD 


\subsubsection{Effects of Magnetosphere and lonosphere}

The magnetosphere is an area in the earth's upper atmosphere in which some of the charged particles coming from the sun (both positively and negatively charged) are captured. Because these charged particles are moving, they create a magnetic field.

The magnetosphere causes shorter period variations called micropulsations. Micropulsations have a broad range sf duration from a fraction of a second up to an hour, with amplitudes of a fraction of a gamma to a few hundred gammas. Micropulsations occur on a random basis any time of the day or night and are related to magnetic storms which occur suddenly and simultaneously around the world. Magnetic storms cause variations of up to several hundred gammas and may last several days. It is important to note that these variations are very large-area variations. Thus, all but the most rapid and severe effects may be mitigated through proper survey techniques such as keeping a base station magnetometer which will record these variations. Then the variations may be subtracted from the survey magnetometer readings.

The ionosphere is also part of the earth's outer atmosphere and contains enough ions and electrons to cause large-area disturbances. This is referred to as the diurnal variation and appears to be a daytime phenomenon in which the earth's total field will increase or decrease by as much as 200 gammas, starting at daybreak and concluding about dusk (Figure 7). The charged particles coming from the sun strike the earth's upper atmosphere, then move about forming large electrical currents which, in turn, produce magnetic fields. Eventually, as these particles move about in the ionosphere, they will begin to lose some of their energy and will recombine to lose their charge as well as their ability to produce a magnetic field.

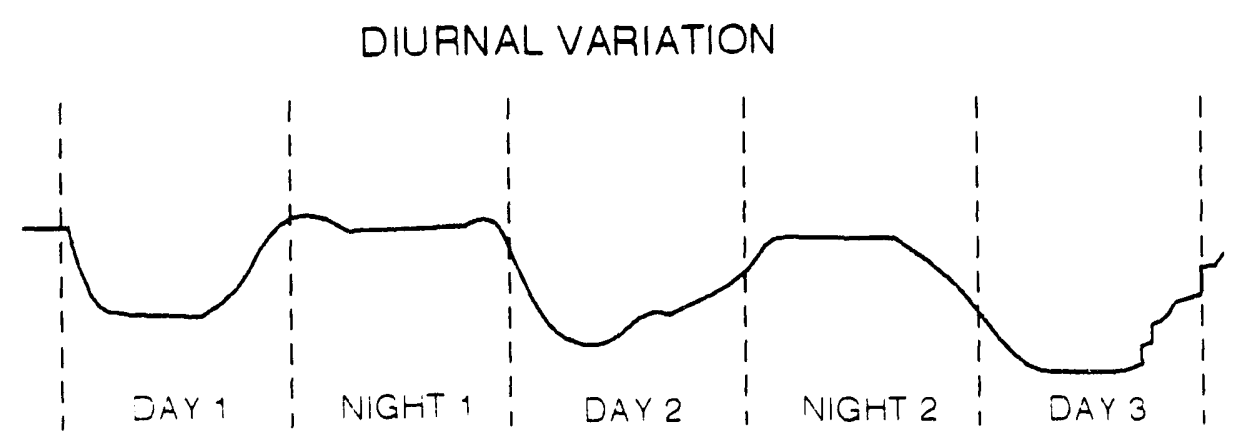

FIGURE 7. LARGE-AREA DISTURBANCE: DIURNAL VARIATION

The area of the highest concentration of charged particles is at a point directly facing the sun. As a point on the earth passes beneath this area in the ionosphere, the magnetic field of the ionosphere and the earth's magnetic field add or subtract to form the diurnal variation. The night side of the ionosphere has few charged particles moving about because, by then, most of the particles have recombined. Here, the ionosphere's magnetic field is negligible so it has no effect on the earth's total field.

A variation of the strength of the solar wind (the term applied to the stream of charged particles emanating from the sun) will cause a corresponding variation in the magnetosphere and the ionosphere, therefore affecting the earth's total magnetic field. Solar wind variations are caused by magnetic storms in the sun, which are characterized by sunspot activity. In times of extreme sunspot activity, field fluctuations might be so rapid and of such magnitude that accurate measurements are impossible. However, these conditions are not common and would only temporarily affect a survey.

\subsubsection{Anomalies}

An anomaly is a variation in a group of magnetic measurements which indicates the presence of a magnetic target. There are four common causes of magnetic anomalies: 

A. Remanent (permanent) magnetization
B. Induced magnetization
C. Thermo-remanent magnetization
D. Changes in the soil's magnetic susceptibility

Remanent, or permanent, magnetization occurs when an object has become magnetic, somewhat like a bar magnet. This is generally the strongest form of magnetization and is independent of ambient field direction. Therefore, it could have any directional orientation. Some substances might become magnetic because they are composed of small magnetic microcrystals. Normally these microcrystals are randomly orientated and, thus, have no overall magnetic moment. However, if these microcrystals become aligned to any degree, an overall magnetic moment is produced and the substance becomes magnetic.

Induced magnetization refers to the action of the magnetic field on a material. The ambient field is altered so that the material in the field behaves like a magnet (Figure 8). The strength of the anomaly is dependent on the strength of the field around the material and the material's ability to alter the field. The relative ability of a material to alter the surrounding magnetic field is called its magnetic susceptibility. This is the process by which magnetite is generally considered magnetic, and the magnetic susceptibility of most other soils is measured by their magnetite content. Most metal drums, pipes, well casings, and holding tanks create anomalies due to induced magnetization.

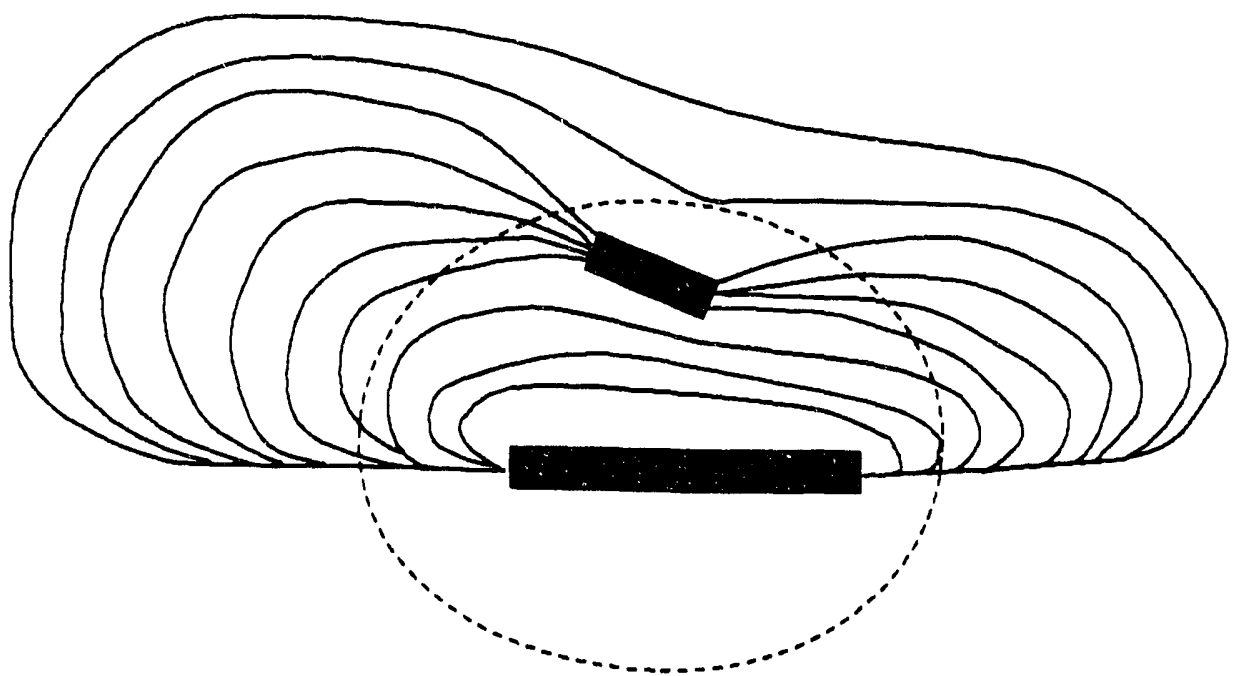

FIGURE 8. INCLUDED MAGNETIZATION: CHANGING AN AMBIENT FIELD

Thermo-remanent magnetization is the process of making substances magnetic by melting them in the presence of a magnetic field. When a substance containing magnetic microcrystals is heated to the point of melting, the microcrystals are free to reorientate themselves from a normally random orientation to an alignment with the earth's magnetic field. When the substance solidifies, the microcrystals are "frozen" in this orientation, producing a permanent magnetic field. During a survey, this process is used to detect objects of archaeological significance such as glass bottles, kilns, or pottery.

Changes in the soil's magnetic susceptibility can be caused by chemical reactions of the ferromagnetic constituents of the soil in the presence of organic matter. This is similar to magnetic variations which are caused by soil of one level of susceptibility being replaced by that of greater or lesser susceptibility. The process of changing the magnetic character of the soil due to chemical reactions is 
not as well documented as other processes, but is thought to be related to organic compounds or humus-enriched structures converting iron oxides in the soil from being weakly to strongly ferromagnetic. Some success has been reported in finding landfills and archaeological sites based, in part, on this process.

\subsection{Target Type and Detectability}

There are many types of objects, soil types, fills, and voids (trenches or holes filled with material of greater or lesser magnetic susceptibility) which produce anomalies that may be detected in a survey. There are three major factors that determine what can actually be located in a survey.

First, the strength of the anomaly must be determined. For instance, in attempting to detect an underground water line, a thick steel or iron pipe would produce some sort of anomaly, but a plastic pipe would produce none.

Second, the distance to the target must be determined. The strength of any magnetic field decreases with distance. In general, a 55-gallon drum can be detected at 10 feet. In conducting a ground survey, a 55-gallon drum buried at 5 feet could be detected. However, while conducting an airborne survey with the magnetometer at an altitude of 50 feet, it is doubtful that such a drum could be detected.

Third, the level of cultural noise must be determined. The strength of an anomaly decreases with distance. If there is a significant amount of extraneous magnetic material (fences, rebar in concrete) in the survey area, then the magnetic field produced by the desired target might be masked by the undesired magnetic fields of the much closer, but unimportant material.

There are some general guidelines about what type of target can be detected and at what distance (as indicated by Table 1 and Table 2). These guidelines do not indicate the depth at which an object may be buried and still be detected; they are only an indication of the distance from the magnetometer at which an object can be detected in either a ground survey or an aerial survey. Also, the detectable distance of any object can te severely limited by adverse soil conditions.

\section{TABLE 1. MAXIMUM TARGET DETECTABILITY DEPTH}

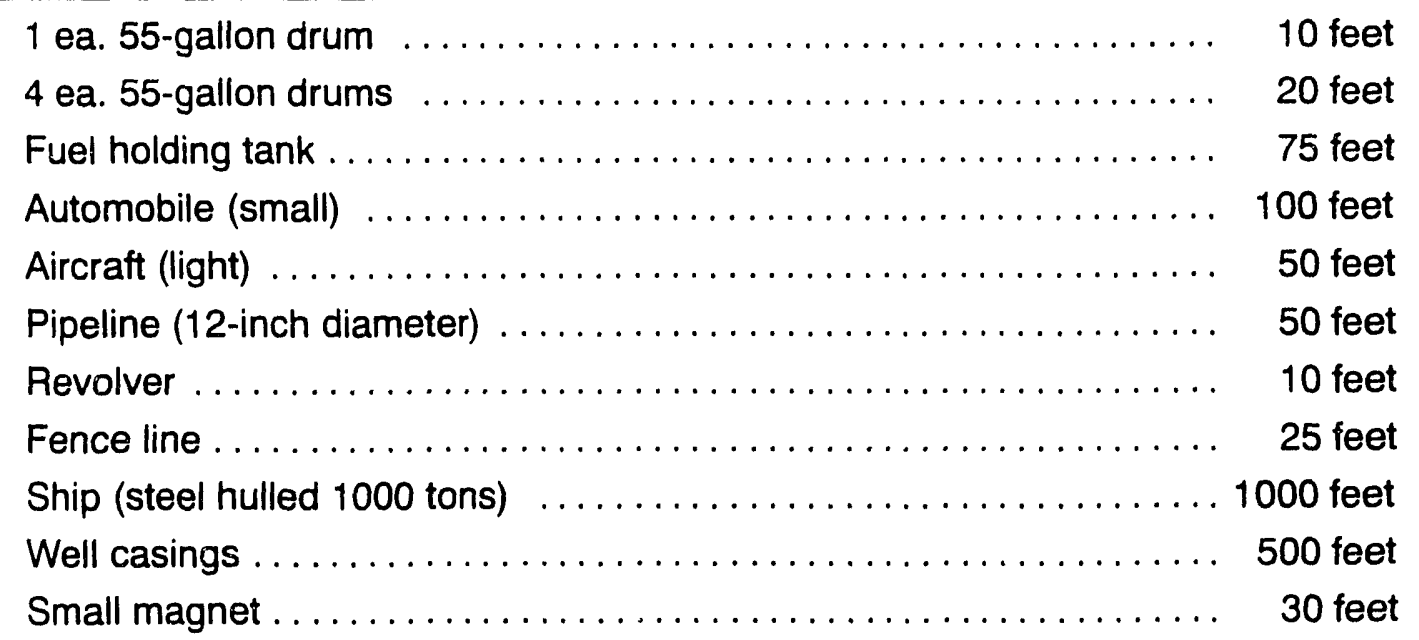

Adapted from a chart in Applications Manual For Portable Magnetometers by S. Breiner, p.46. In this version, distances should be considered as rough estimates only. 


\section{TABLE 2. APPROXIMATE MAGNETIC STRENGTH OF OBJECTS WITH DIFFERING AMOUNTS OF IRON CONTENT}

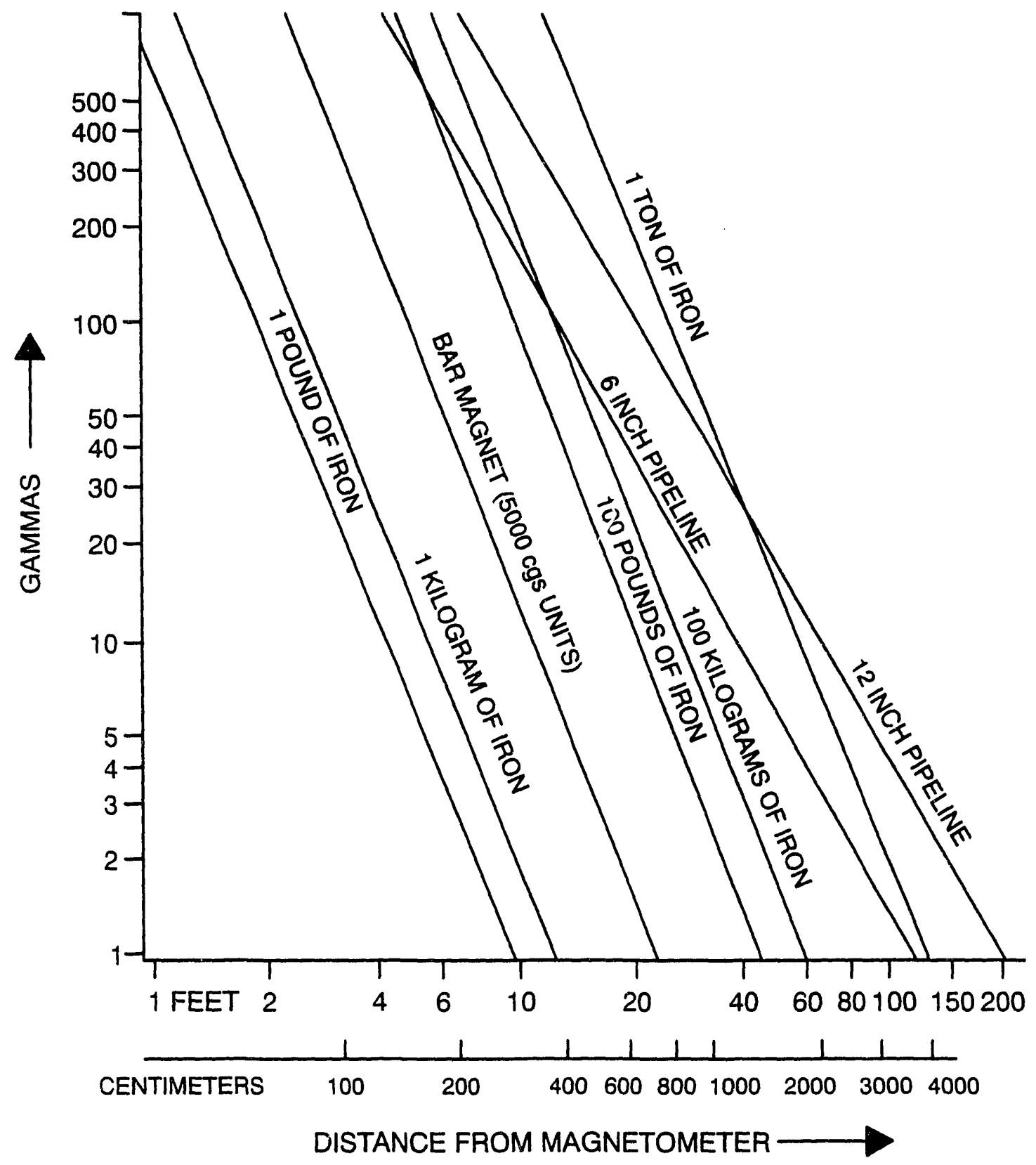

Taken from “Applications Manual for Portable Magnetometers” by S. Breiner, Geometrics, p 43

\subsection{Survey Techniques}

There are some common techniques which are used to conduct a magnetometry survey. A competent contractor should be able to make suggestions or variations in survey techniques if new equipment, types of targets, or local conditions warrant them.

The most common technique will use two magnetometers. One magnetometer is kept as a fixed-base station to measure changes in the local field that might be caused by magnetic storms, 
micropulsations, and diurnal variations. These are wide-area effects, and their variations must be removed so any anomalies are not masked.

The search is then conducted by making readings at specific sites in the search area with a survey magnetometer and mapping out these readings (after all known natural variations have been removed). Next, an analysis is made of any localized area for larger or smaller readings which might indicate that a target could be buried there. The locations of the readings will be along some preselected grid over the search area. Rectangular grids are usually chosen for two reasons. First, accurate mapping of the data is very important for determining anomaly shape and size. Using an accurate positioning system is critical. Second, a search area is often retraced using traverses perpendicular to the original traverses. This will further reduce the effect of variant cultural noises and any problems with reading deviation.

Grid spacing is also an important survey factor and should be determined by the size of the search area and the types and depths of the targets being sought. For example, if an acre of land were being surveyed for a shallowly buried, 55-gallon drum, then a ground search with a grid spacing of three to four feet might be appropriate. In contrast, in surveying a few square miles for a buried landfill of metal drums and well casings, an airborne search with a spacing of fifty to a hundred feet might be more appropriate.

\subsection{Associated Technologies}

Magnetometry can be used to find objects made of magnetic material, some landfills, and some hydrocarbon plumes. However, many metals or geologic landforms might not be detected by magnetic means. Electromagnetic inductive methods are available which will further characterize an area to help locate these targets. In many instances, a contractor will have both sets of survey equipment capable of being flown and recording at the same time. Gravimetry can also be used to determine the actual perimeter of landfills or depth to water tables.

\subsection{Questions to ask Survey Contractors}

A. Do you perform both aerial and ground surveys?

The results of an airborne survey may suggest that a more detailed survey is required. $A$ ground survey over a smaller section of the total search area might be desirable.

B. Are your aerial surveys conducted using a helicopter or a fixed-wing aircraft?

Measurements taken while using a helicopter as the survey platform are usually more precise than those taken from a fixed-wing aircraft. Because of the slower speed of the helicopter, an instrument package can be lowered from the aircraft over specific survey sites, and the spacing between measurements can be fairly close. Measurements taken using fixedwing aircraft may not be quite as accurate, but a much larger survey area can be covered in a shorter length of time.

C. Does your survey instrument package use a total field or gradient technique?

A proton precession magnetometer (total field technique) does not work well in areas of high magnetic variations due to natural interference. In this case, a gradient technique might be best. A contractor familiar with the local geology should be helpful in deciding the best technique for the survey. 
D. What is the size of an object and at what depth can it be buried and still be detected?

Often contractors and manufacturers will state the sensitivity of their instrument packages. This might be usef ' in some cases, but the bottom line of any survey is what can be detected. For instance, a cesium vapor magnetometer flown on an aircraft might have a sensitivity of .01 gamma. However, when searching for a small target in an area of high cuttural noise, such an instrument might still not be able to find the target.

E. How are the survey data mapped?

Variations in readings due to diurnal variations, magnetic storms, micropulsations, and cultural noise must be removed from the data before anomalies can be determined. Typically, after the unwanted components of the data are removed, a map is drawn showing the locations and shapes of any anomalies. There are several methods available; however, only one has been mentioned in this text. A competent contractor should be able to discuss his company's method and explain how variations are removed from the data and in what form the results will be presented.

F. What other survey techniques are you capable of performing?

Many contractors are capable of using several survey techniques. The electromagnetic inductive technique is probably the most common. A good contractor might be able to suggest a complementary method which might enhance the results based on the type of target, the local geology, or cultural noise.

G. What items are included in the survey costs?

Some of the factors to be considered in addition to the actual survey costs are: the processing costs, the labor, and any special licenses that might be required.

H. How accurate is your positioning system?

Accurate mapping of anomalies can only be done if there is a high degree of confidence in the position of the readings. Moreover, the altitude of the magnetometer at the time of the readings is crucial to any survey. This will indicate how small an object could have been detected and its approximate subsurface depth. If the survey area is small enough, a microwave triangulation system is preferred, although a GPS or other system might be acceptable depending on the survey requirements. 


\subsection{SYNTHETIC APERTURE RADAR SURVEYS}




\section{SYNTHETIC APERTURE RADAR SURVEYS}

\section{Synopsis}

Technology: Synthetic Aperture Radar

May Detect: Oil spills at sea

Abandoned stockpiles of drums and industrial equipment

Waste pollutant presence and migration direction

Underlying principle: Doppler and phase shift corrections to a radar return signal (echo) in order to improve the resolution of the imaging radar

Optimum geologic conditions: Imaging the topography of barren ground; however, excellent results can also be obtained for imaging topography through a thick, vegetative cover

\section{Extended Discussion}

\subsection{Introduction}

Synthetic Aperture Radar (SAR) is a form of side-looking imaging radar used to map large areas of terrain, to inventory vegetative types and conditions, and to determine the extent of oil spills at sea. Although subsurface investigation is possible with this technology, the SAR's greatest advantage is its ability to image through forest and thick vegetative canopies. Abandoned stockpiles of drums and industrial equipment can be found with this technology, but more often the mapping of terrain conditions and topography enables a survey to determine the presence of waste pollutants and their possible migration direction.

\subsection{Instrumentation}

The SAR is an airborne radar technique used to survey large areas. This type of side-looking radar examines an area which lies below and slightly to the side of the flight path of the airborne radar platform (Figure 9). The complete SAR system is composed of: a signal generator, transmitter and receiver circuitry and their common antenna, a filter section, a recording device, a data processor, and some form of output or viewing device. The output can be in any form, varying from an image of near photographic quality to a video tape recording of the area.

\subsubsection{Single Frequency Pulse}

The SAR receives information about a target from the echo return of a transmitted electromagnetic pulse (EMP). The EMP's direction is perpendicular to the flight direction, and the radar's resolution capabilities along the direction of travel of the EMP are directly dependent on the width of the EMP emitted by the radar unit. A narrow pulse width is required for fine resolution in the range direction; 
however, this dependence of range resolution on pulse width is complicated by the requirement for long-range distance capability which is a function of the EMP transmitted power. Because of practical limitations on the radar circuitry, there is a limit on the amount of power that can be transmitted in a narrow pulse. Therefore, a greater range distance requires a wider pulse width. For some survey applications, a balance is found between resolution and range, and a pulse of a single frequency EMP is used to acquire an image.

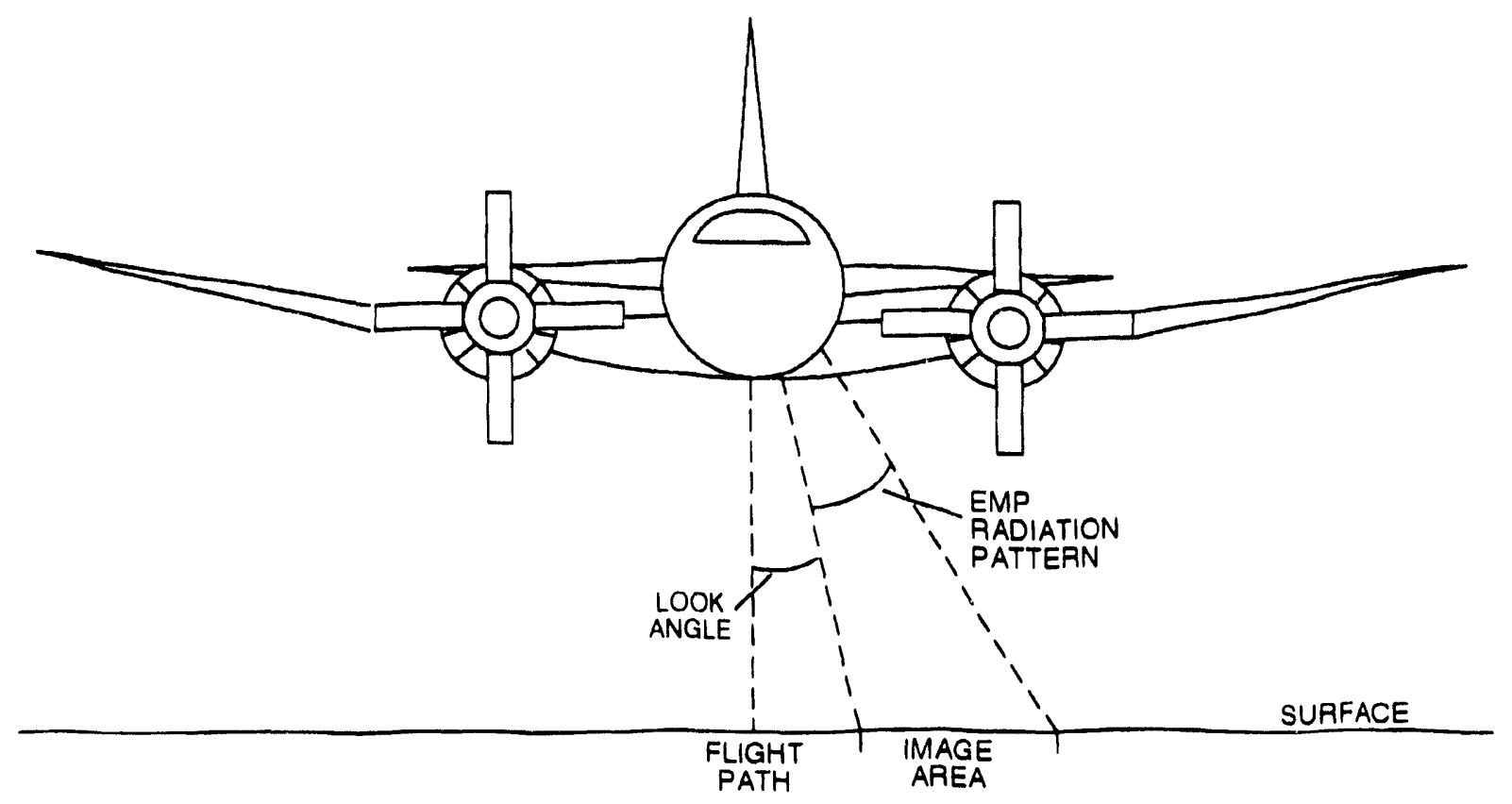

FIGURE 9. SYNTHETIC APERTURE RADAR PLATFORM

\subsubsection{Varying Frequency Pulse}

In other surveys, the frequency of the electromagnetic waves in the pulse is forced to vary. For example, at the beginning of the pulse, the frequency might be transmitted at a fairly slow rate. Then the wave frequency is increased so that the frequency is much higher at the end of the pulse than at the beginning of the transmission. This is referred to as a Frequency Modulated (FM) wave pulse, and the process, called "chirping," substantially increases the transmitted power of the EMP.

A much longer pulse width greatly increases the radar's effective range. By using a filter circuit in the receiving circuitry, only ihat portion of the return which corresponds to a narrow frequency range will be analyzed, and only a narrow portion of the pulse will be observed. In this manner, long-range distance and fine-range resolution can both be obtained. This discussion will focus on the single frequency electromagnetic wave of the SAR's EMP. However, the same capabilities exist for an FM pulse if there is proper filtering and processing of the return echo.

\subsubsection{Determining Resolution Capability}

The SAR is sometimes referred to as an imaging radar because of the type and quality of the output produced. In two-dimensional imaging, resolution capability is determined by different processes along each of the two axes of the image. One direction is determined along a line which is perpendicular to the flight direction of the aircraft containing the SAR unit. Resolution in this direction is referred to 
as range resolution or cross-track resolution. Resolution in this direction is a function of the EMP pulse width and range resolutions to almost one half the effective pulse width of the EMP can be obtained.

The second direction of resolution is along a line which is in the flight direction of the aircraft. Resolution in this direction is referred to as along-track, cross-range, or azimuthal resolution, and resolution in this direction shows the definite advantages of the SAR over standard side-looking radar.

\subsubsection{Azimuthal Resolution and Synthetic Aperture}

The largest difference between standard side-looking radar and the SAR is the way that the azimuthal resolution varies with increased range distances. The EMP radiating from the transmitting antenna expands as it travels away from the antenna and eventually becomes so diffuse that the receiving antenna cannot detect any return echo. The end effect is that the transmitting antenna radiates an energy pattern which resembles a cone with the transmitting antenna at its apex. The extent of expansion of the EMP is referred to as the antenna's beam width, which is measured in degrees. For imaging applications, beam widths of 0.1 to 2.0 degrees are not uncommon.

In standard radar, the resolution in the azir.iuthal direction is closely related to the beam width of the antenna. Even if the beam width were as small as 0.5 degrees, the resolution of such a system would be 13.2 meters at $3 \mathrm{~km}$, and 132 meters at $30 \mathrm{~km}$-exceptionally poor at long range distances.

To increase the resolution, the radar beam width must be narrower. This is referred to as beam sharpening. For standard radar, one way to accomplish beam sharpening is to make the diameter of the antenna larger. The larger the antenna, the sharper the beam profile. For an airborne system, mounting a larger antenna of sufficient size to resolve targets in the azimuthal direction to achieve the same dimension as in the range direction (at long range distances) is simply not a viable option.

The SAR, however, employs a technique which uses the aircraft's forward motion and the corresponding changes of phase and frequency of the echo return, discussed below, to narrow the angle of view of the received signal and so effectively increase the size of the antenna. The diameter of an antenna is called its aperture; thus, this method of artificially increasing the effective size of a radar antenna is called Synthetic Aperture Radar.

The time delay between transmitting the EMP and receiving the echo indicates the distance to the target. The amplitude of the return echo indicates the reflectivity or shape of the target. A Doppler shift of the frequency of the return echo indicates a relative velocity between the target and the radar unit, and a phase shifting in the return echo indicates small distance differences. The SAR uses the phase and Doppler shift differences to determine azimuthal resolution.

\subsubsection{Doppler Shift Differences}

The Doppler shift can be described as that phenomenon which causes the pitch of a train whistle to sound higher as the train approaches and lower as the train travels away. In the same manner, the echo return from a target approaching the radar unit will have an increase in frequency, and a target receding from the radar unit will cause the echo to have a lower frequency due to the relative velocity between the target and the radar unit.

If the aircraft containing the radar unit were traveling directly toward the target, then a Doppler frequency shift of $2,000 \mathrm{~Hz}$ to $3,000 \mathrm{~Hz}$ would be detected. Even if the target were substantially offset from the line of travel of the radar unit, there would be some Doppler shift. However, for a target which 
lies along a line exactly perpendicular to the radar unit and its line of travel, there would be no frequency shift because, at that point, there is no target velocity toward or away from the radar unit. Slightly before and after this point, there is an increasing Doppler frequency shift, but exactly along this perpendicular line there is none. Thus, by ignoring all echo returns with a Doppler shift, an extremely narrow beam width can be approximated (Figure 10). This narrow beam width constitutes the synthetic aperture discussed above.

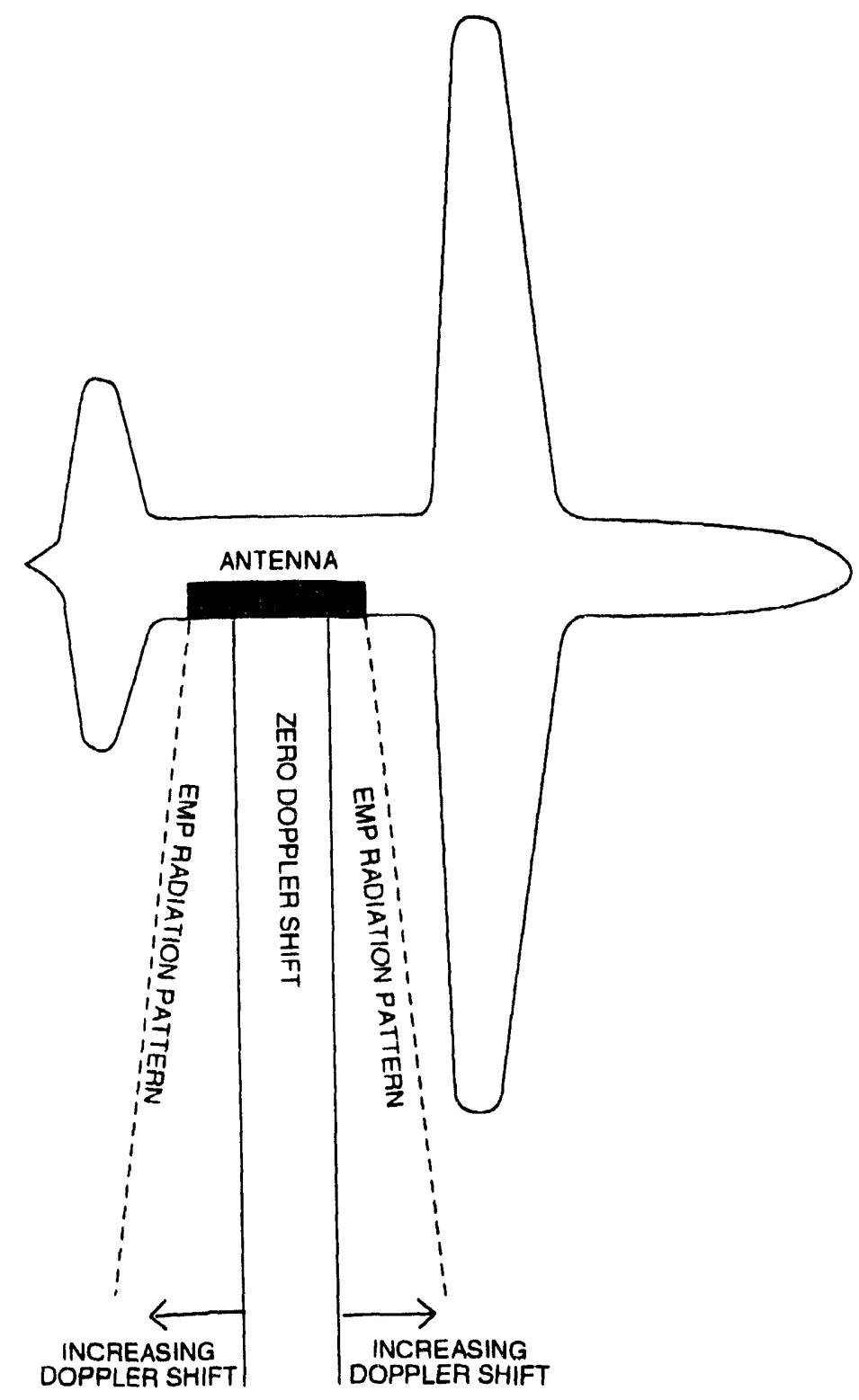

FIGURE 10. DOPPLER SHIFT ZONES

\subsubsection{Phase Shift}

The phase shift is related to the Doppler effect. There are two different ways to represent the radar wave packet: the plane wave or a sinusoidal electromagnetic wave snaking its way along the EMP's direction of travel (Figure 11). The distance between the crest of one wave and the crest of the next wave is always exactly the same. 


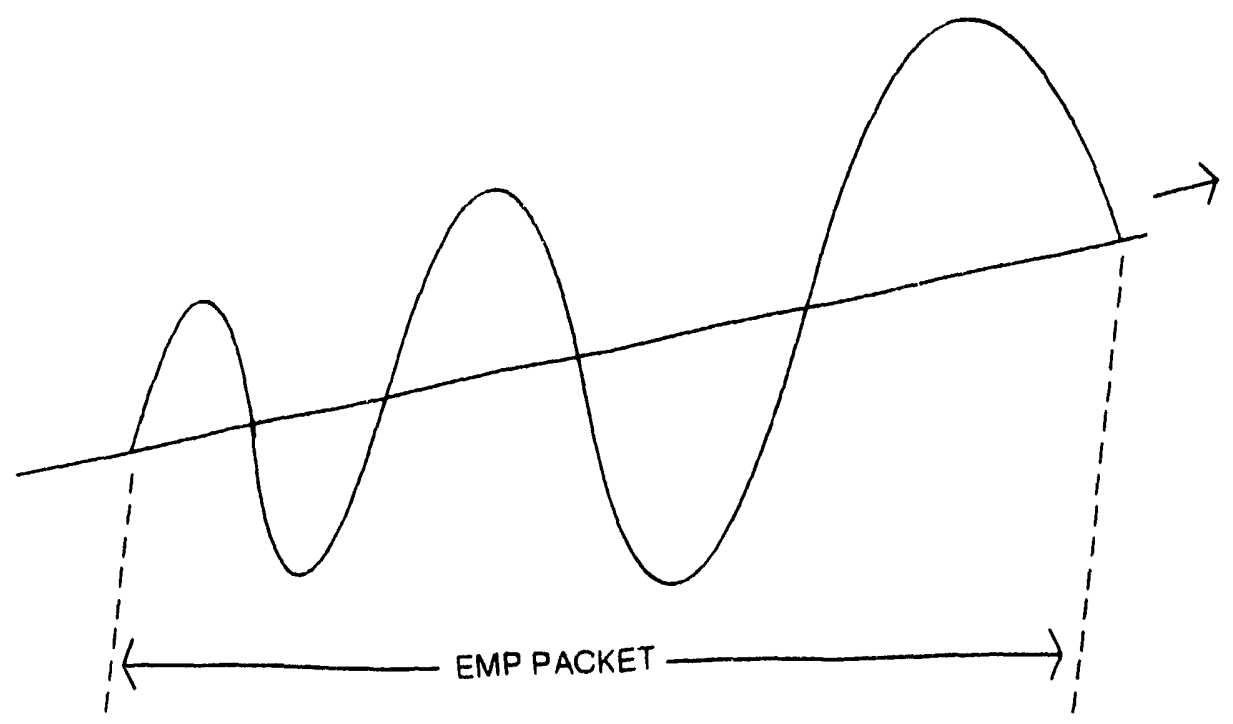

FIGURE 11. SINUSOIDAL ELECTROMAGNETIC PULSE REPRESENTATION

Figure 12 illustrates that the distance to different points on a planar surface at a perpendicular distance, $R_{0}$, from the radar unit varies. As the echo returns from two different portions of a target, the distance traveled by the two portions of echo (often thought of as two different echoes) is different. As these echoes return to the radar unit, the receiver will first detect the electromagnetic waves along different portions of their respective wave shapes. This difference in detection between the two echoes is referred to as a phase difference.

When an echo return is processed with a correction made for only the Doppler frequency shift of the echo, the system is referred to as an unfocused SAR system. The azimuthal resolution of this system is far superior to the standard side-looking radar, increasing resolution by as much as a factor of 10 at the far range distances. When corrections are also made for the phase shift, the system is referred to as a focused SAR system. The azimuthal resolution of a focused SAR system is finer at the close range distance then for the unfocused SAR systems and remains at a constant measurement for the entire range distance of the system. The azimuthal resolution of a focused SAR system depends on the actual antenna dimension and the wavelength of the electromagnetic waves emitted, but not on the range distance.

For a focused SAR system, corrections for Doppler frequency and phase shifts must be made to the data. Therefore, data processing is a crucial part of SAR imaging. Quite often data taken during a survey is stored on magnetic tape to be fully processed at a later time. However, high speed microprocessors now allow some systems to produce a preliminary video output in real time as the survey is being taken (Liu, 1988).

One data processing function which is related to resolution is the statistical averaging of multiple echo returns from a single target. As an aircraft equipped with a radar unit travels along its flight path, it produces a pulsating side-looking radar beam pattern which travels in the same direction as the aircraft. As the aircraft passes a target, the target will lie within the beam fattern for a period of time which is dependent on the aircraft's velocity and the beam width of the radar. The radar transmits electromagnetic pulses at a rate of several thousand per second, so usually a single target will return many echoes which can be corrected for phase and Doppler shifts and then processed. This adds to the resolution because of a phenomenon called scintillation. 
When the amplitude of the target echo is artificially large or small, it is called scintillation and it is primarily caused by several echoes returning from different sections of the target. As siated earlier, echoes returning to the radar unit that have traveled differant ósstances are detected at different points along the electromagnetic waves. This $s$ referred to as a phase shift. The radar may not be able to distinguish between the phase shifts of the returning echoes and may add their returns, thus making the comrined echoes artificially high or artificially low. By taking many looks at a target from slightly different angles and statistically averaging all the echoes into one combined echo, a better determination of the target's size or shape can be made.

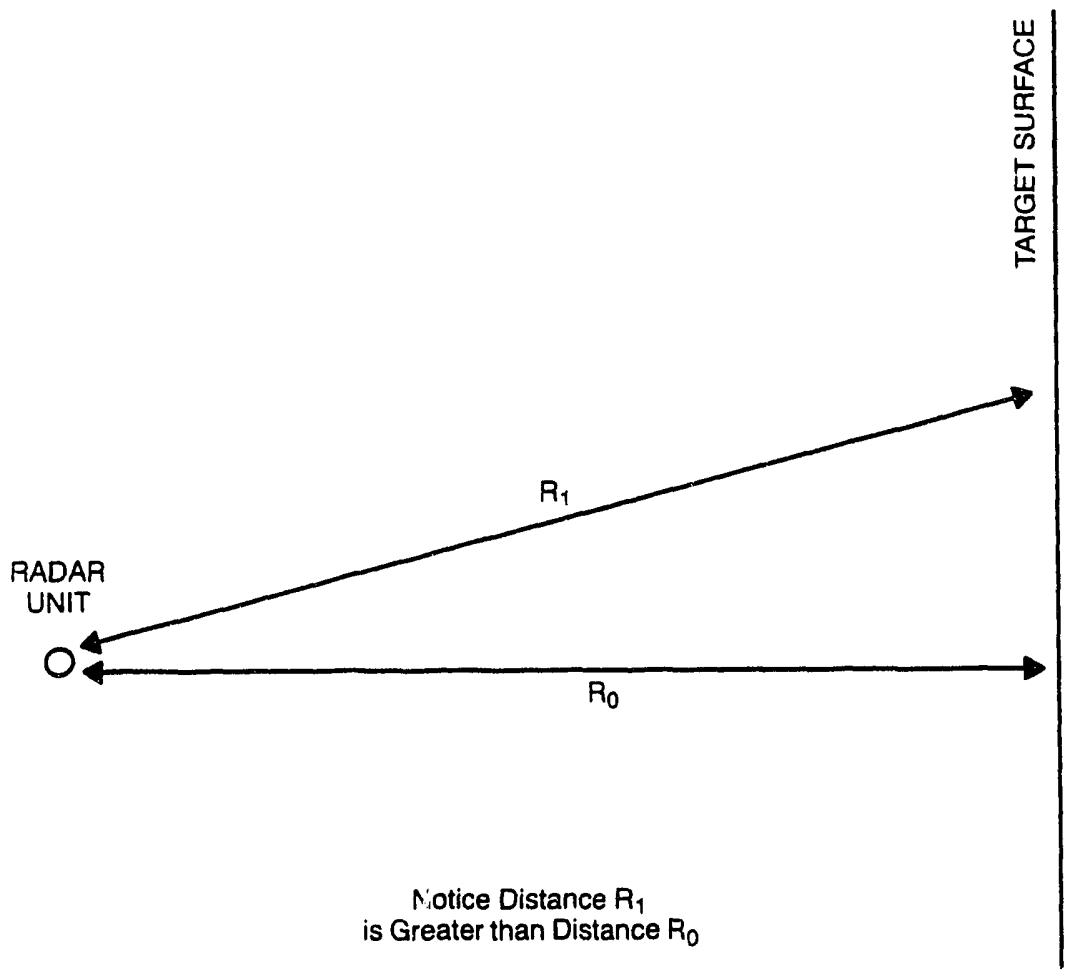

FIRURE 12. DISTANCE VARIANCES

\subsubsection{Transmitter and Receiver Polarization}

The electromagnetic wave has been described as wriggling from side to side as it travels in the general direction of the EMP. The side-to-side motion is confined to a certain plane. If it is a vertical plane, then the electromagnetic wave is vertically polarized. If it is a horizontal plane, then it is horizontally polarized. Transmitters and receivers can operate as either horizontally or vertically polarized.

SAR systems are sorretimes designated by their polarization capabilities, a two-letter designation with the first letter representing the transmitter polarization and the second letter representing the receiver polarization. Thus, an $H H$ system would be a system which emits a horizontally polarized EMP and receives only horizontally polarized echoes. A VV system would be the same, but for vertically polarized waves only. $H V$ and $V H$ are referred to as cross-polarized systems which detect echoes of the opposite polarity than the transmitted pulse.

\subsection{Nature of the Measurements}

Light is one form of electromagnetic waye, and there are many similarities between light and radar beams. Possibly the most important concepts of radar which can be understood in terms of light-like 
behavior are those of reflectance and scatter. As a light beam strikes a smooth reflector at an angle (angle of incidence), it is reflected, and the angle at which it will be reflected (angle of reflectance) will be equal in magnitude to the angle of incidence. For an idealized light ray on a perfectly smooth reflector, all of the energy of the incident light ray will be reflected according to this principle (see Figure 13). If the reflecting surface is rough, then the reflected light will experience some degree of scattering (see Figure 14). When the incident light is reflected in a number of directions, it is referred to as diffuse scattering or reflection. Except for specular (mirror) surfaces, reflected light has both specular and diffuse components.

The roughness of an object determines the amount of diffuse scattering of the electromingetic wave. A surface can be considered rough if its texture varies by more than one sixth of a wavelength. For a radar unit operating at $1 \mathrm{GHz}$ (wavelength of 0.3 meters), this would mean any variations of over 5 centimeters would cause some diffuse scattering.

\subsubsection{Terrain Effects}

A practical application of this principle is the effect the survey area's terrain slope may have on the reflectance of a radar echo. Even if the surface being illuminated were smooth, if the slope caused the radar beam to strike its surface at a nearly perpendicular angle, a very high reflectance toward the radar unit could still be detected. Conversely, the images of lakes are often dark in a Synthetic Aperture Radar image because the EMP strikes the smooth water at such an angle that the echo is directed away from the radar unit. Thus, when a survey is being planned, the flight path should be flown to derive the maximum benefit of the topography of the area. In SAR terminology, the direction from the radar to a target is called the "look direction." The angle at which the radar looks from the horizontal is referred to as the "look angle."

SAR images are formed by mapping out areas in terms of the distance from the flight line and the strength or brightness of the echo. Sequential looks are pieced together to form the total image. The echo brightness is determined by some system considerations, but the most important factors are those of the target area itself. As previously stated, the roughness and slope of the terrain affect the brightness of a return echo.

\subsubsection{Target Composition and Size}

The size of the target as a ratio of the wavelength of the system is one factor determining reflectivity. $A$ thin crop cover over a field might not be detected at longer wavelengths; however, at shorter wavelengths the crop cover might be detected as well as the moisture content of the crop and the condition of its leaves. Some variations due to the polarity of the EMP are possible. Tall, standing narrow objects are best detected by a $V V$ system, and objects lying on their sides are best detected by $H H$ systems.

When an EMP strikes an object, part of the pulse is reflected, but part of the pulse continues through the target. Conductive targets reflect almost all of the EMP and image as bright spots on an SAR image. Other objects might appear almost transparent to the radar as the EMP travels through the target and may be reflected by a deeper soil strata. Thie depth of penetration is determined by the size of the object, its conductivity, and the wavelength of the radar system.

\subsubsection{Target Limiting and Determining Factors}

As an EMP penetrates an object, some of the energy of the EMP is reflected either to or from the radar unit. As the pulse travels through the target, it causes atoms in the materials to vibrate and takes 




NOTICE THAT THE ANGLE OF REFLECTIONS IS EQUAL TO THE ANGLE OF INCIDENCE

FIGURE 13. SCATTERING OF REFLECTED LIGHT (SMOOTH SURFACE)

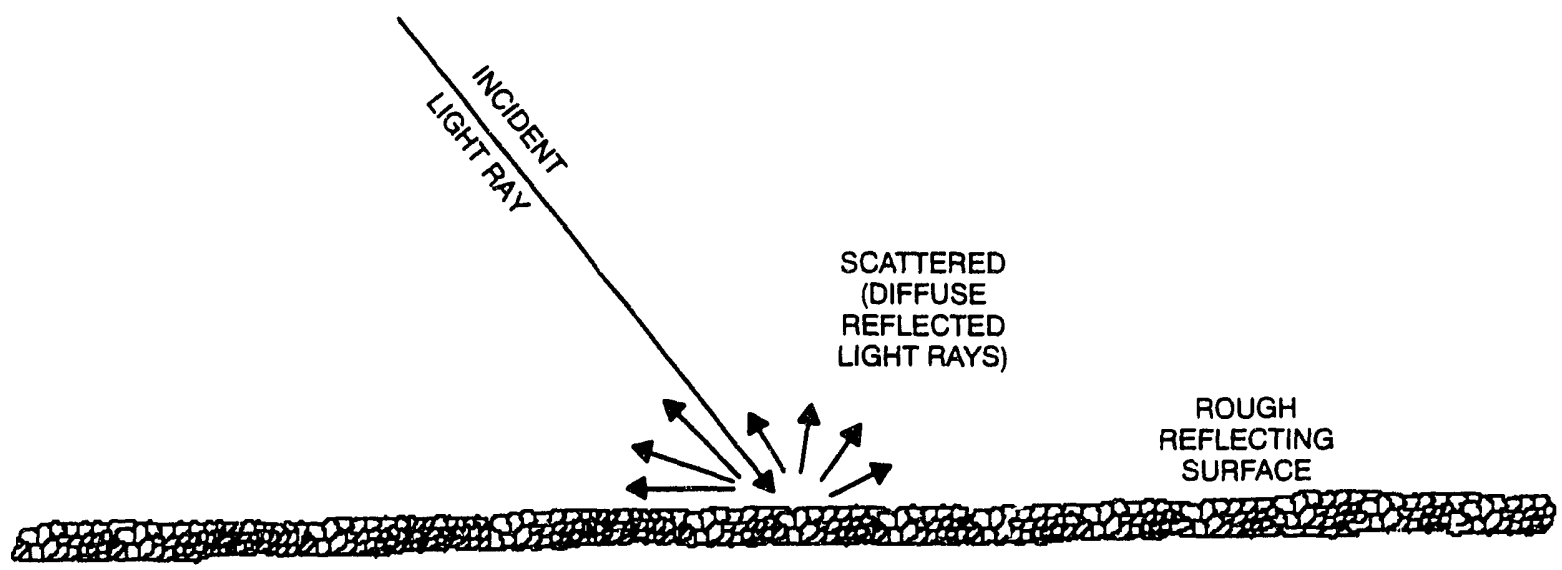

FIGURE 14. SCATTERING OF REFLECTED LIGHT (ROUGH SURFACE)

additional energy away from the EMP. This is referred to as signal attenuation. The deeper an EMP penetrates an object, the more energy is absorbed by the material.

All materials absorb some energy, but clay and water (especially salt water) $\because$ among the most absorbent. The depth of penetration of a radar pulse is, thus, dependent on the composition of the soil and its water content. This might limit some investigations. For example, soil in southern Nevada has a high clay content which is very conductive, making subsurface radar imaging impractical. However, in other areas, subsurface river beds and geologic structures have been successfully mapped by SAR methods.

The polarization of the electromagnetic wave can help determine the physical orientation of some long, slender reflectors or some geologic structures. For example, geologic ridging which is nearly horizontal is best imaged by horizontal polarization.

The topography of an area can be determined by the shadow it will cast due to the radar's look angle (Figure 15). In this figure, a radar EMP is imaging two hills. As the EMP is transmitted and expands, its curvature diminishes to the point that the EMP can be thought of as a plane wave. As the bottom part of the EMP strikes the first hill, it is reflected back, but the upper portion of the wave continues until it reaches the second hill. The time delay between the echo return from the first hill and the echo return from the second hill is referred to as the first hill's shadow. A slightly more horizontal EMP would cause 
a longer shadow, and a much more horizontal wave would cause a shadow which might completely obscure the second hill.

Shadowing is one method by which structure heights can be determined, but too much shadow can hide detail. For SAR, look angles of 50 to 85 degrees from the horizontal are typical, with 85 degrees being the look angle to the near edge of the image.

\subsection{Target Type and Detectability}

The characteristics of the SAR which determine the type of target that can be found are: the system's resolution, frequency, polarization, energy output, and the platform on which it is flown. SAR systems are flown on aircraft, the space shuttle, and in satellites. Much research is being conducted to improve system performance, but currently, typical commercial resolutions are 1.5 meters by 1.5 meters for aircraft systems (Wagner, 1991) and 15 meters by 15 meters for satellite-based systems (Wirin, 1991).

Though little attention has been paid to subsurface investigations by commercial contractors, the NASA SAR systems have mapped subsurface river beds in Egypt. Subsurface images are not common; however, stripping away forests and vegetative canopies to expose the underlying terrain is considered the SAR's most desired capability. In this way, the geologic topography can be used to determine the probable direction of migration of spilled pollutants. Because metal is highly reflective, abandoned industrial machinery or stockpiles of waste containing 55-gallon drums would be highly visible regardless of the type of ground cover. Conversely, large pools of water or water-based pollutants would be visible because there would be little echo return.

Because the resolution of this type of radar is rather coarse and the surveyed areas are rather large ( $20 \mathrm{~km}$ by $30 \mathrm{~km}$ is typical), searching for small items such as a few 55-gallon drums is not an appropriate search objective.

SAR images have been used to determine the condition of agricultural crops (Zoughi, 1987). To some extent, the moisture content and leaf size can be determined by higher frequency radars. in those cases where the local flora might have been affected by a ground-based chemical spill or an airborne toxic plume, SAR images might be used to determine the extent of the affected area. Because still water reflects a radar echo away from the radar unit quite readily, a large pool of water-based pollution shows up as resembling a shadow. This could be used to find or inventory ponds of polluted material. Under some conditions, the extent of water migration from a holding pond can also be determined.

During experiments in Germany, sea-based oil spills were mapped using a side-looking radar and a Synthetic Aperture Radar. While the intensity of the SAR return did not allow the extraction of any information about the thickness of the oil spill, the oil slick was detected even when it had diffused to an average thickness of ten micrometers. The oil interacted with the sea water and interfered with the production of the ocean's capillary waves. Capillary waves are rough scatterers and show brightly in an SAR image.

There is a dark spot where the oil interferes with the capillary waves. $V V$ systems appear to be best suited to this type of investigation. Thus, the SAR shows promise for the monitoring and mapping of large-scale oil spills (Bartsch, et al., 1987).

\subsection{Survey Techniques}

Because of the high SAR survey costs and the large-scale image produced with a rather coarse resolution, SAR surveys are not recommended for searching small areas for small objects. SAR surveys 
are recommended for large-scale imaging of the terrain and for determining the condition and moisture content of the vegetative cover. The SAR could also be used to map the extent of sea-based oil spills. The characteristics of SAR which must be coordinated for the different types of surveys are: the frequency of the system, the polarity of the system, and the look direction of the survey flight.
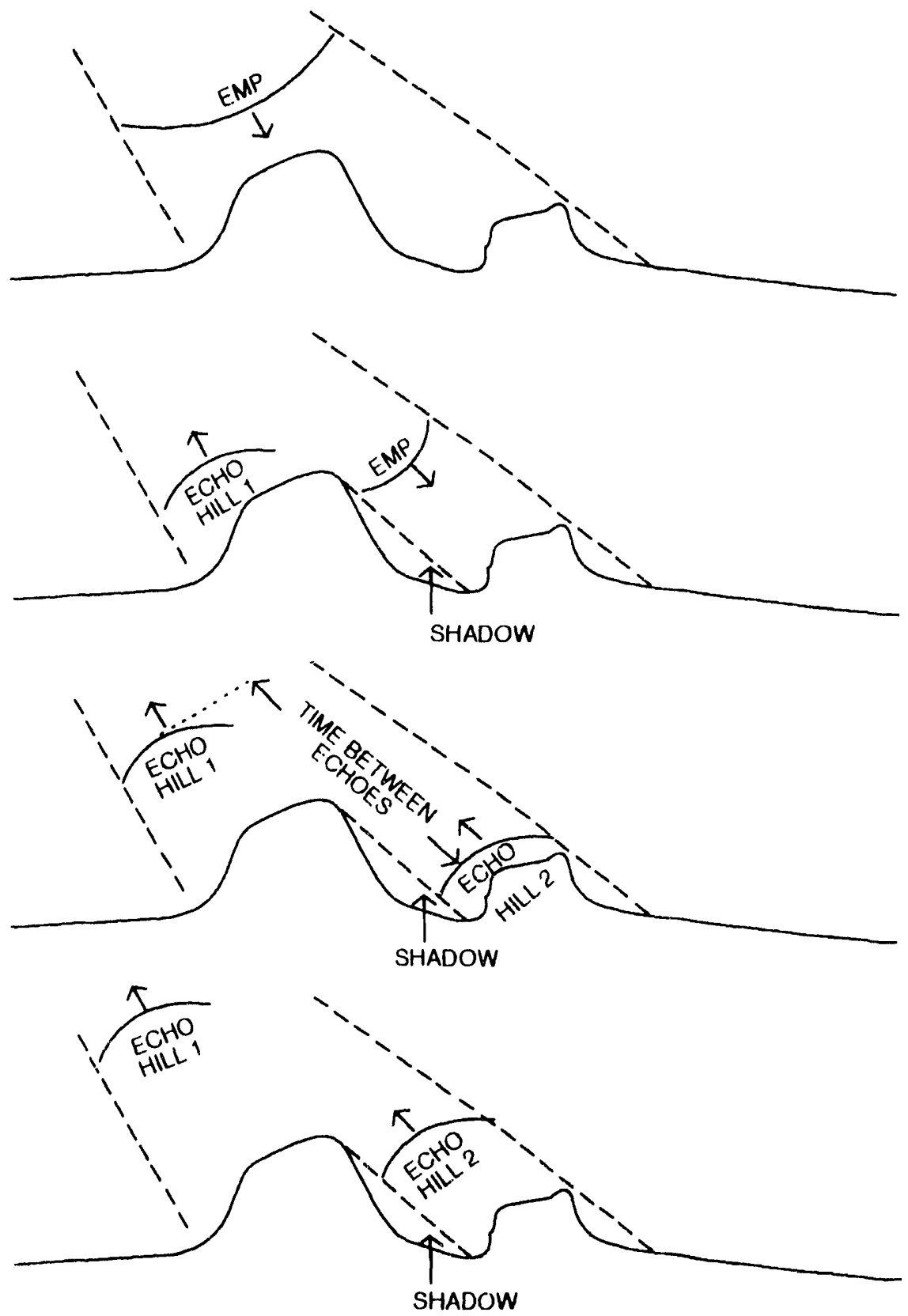

FIGUAE 15. EMP REFLECTION FROM TWO HILLS WITH SHADOW TIME INDICATED

For mapping terrain beneath a vegetative canopy, a system with a lower frequency is necessary. Usually, the resolution needed for this type of mapping requires the use of either a high altitude aircraft or a satellite system. In addition to the EMP frequency, the polarization of the EMP is also a concern. For imaging geologic structures, the proper polarization may vary from point to point. Generally, an $H H$ system is preferred because trees are less visible to such a systern. However, vertical structures would 
also be less visible. If the topography is rough, then the look angle should be chosen so that shadowing and slope reflectivity are optimal. It might be necessary to fly two separate flight paths to obtain two views of an area from different angles to gain the maximum amount of information about an area or resolve any ambiguities about a specific target.

To determine the condition of crops and vegetative cover, a high frequency system is advisable. For such a survey, a low altitude flight path should be chosen. The polarity will depend on what aspect of the survey is of interest. $V V$ polarization will be best for determining some aspects of the vertical stalks, whereas $H H$ will be best for determining the biomass soil cover.

For oil-spill mapping, a high frequency radar should be chosen, and the type of radar platform depends on what is necessary for accurate mapping. A $V V$ system seems to work best, but cross-polarization systems are also being examined.

\subsection{Associated Technologies}

Ground-penetrating radar systems might be used to more carefully examine any areas which show some sort of subsurface SAR anomaly. This would, however, be an extremely limited survey in comparison to an SAR survey. Two technologies which are not discussed in this handbook which could provide additional information for topographical surveys are aerial photography and microwave radiometry. Using an aircraft for the survey platform, aerial photographs of the survey area are taken and examined. In microwave radiometry surveys, a sensor is flown so that reflections from the target are detected from a naturally occurring microwave source.

Laser-induced fluorescence is another technology which might be used to determine soil conditions. The atoms of the soil are excited by a laser, and the reradiation of photons from the substances composing the soil is detected. All substances have a unique pattern of reradiated photons, so a careful examination of the reradiated photons could help detect the composition of the surface and very near surface soil pollutants.

\subsection{Questions to ask SAR Survey Contractors}

A. Is your system a Synthetic Aperture Radar system or a Side-Looking Radar system?

For some purposes, the degradation of azimuthal resolution with range is not a problem, but the type of output image produced by the two methods differs significantly.

B. At what altitude can this system be flown, and how large an area can be imaged?

These values differ between contractors, and most significantly between the platforms of the systems. An aircraft-based system will be flown at an altitude of 1 to $10 \mathrm{~km}$; however, a satellite may possibly be flown at an altitude of $300 \mathrm{~km}$. Aircraft images cover a minimum $10 \mathrm{~km}$ by $10 \mathrm{~km}$, and satellite images can cover as much as $40 \mathrm{~km}$ by $300 \mathrm{~km}$.

C. At what frequency and at what polarization does this system operate?

Lower frequencies have greater target penetration and are used to determine geologic structures. The higher frequencies are best for determining crop cover.

Different polarizations are available as well as combinations of frequencies and polarizations. Sometimes frequencies are given in terms of bands. These bands are designated frequency ranges: 


$$
\begin{aligned}
& \mathrm{Ka} \text {. 26.5 - 40 } \mathrm{GHz} \\
& \mathrm{K} \ldots 18-26.5 \mathrm{GHz} \\
& \mathrm{Ku} \ldots 12.5-18 \mathrm{GHz} \\
& X \ldots 8-12.5 \mathrm{GHz} \\
& \text { C... } 4-8 \mathrm{GHz} \\
& \mathrm{S} \ldots 2-4 \mathrm{GHz} \\
& \mathrm{L} \ldots 1-2 \mathrm{GHz}
\end{aligned}
$$

D. What are the look angles of this system?

Look angles are sometimes given as the angle from the horizontal and sometimes the angle from the vertical. The look angle will vary over the range of the image. In some systems, this factor is corrected during processing.

E. What are the resolution capabilities of this system?

If a specific target is being sought, then a finer resolution is necessary. However, if the survey is to map the topography of a large area or the dimensions of an oil spill, then a coarser resolution might be acceptable. There is usually some correlation between the extent of an area covered and the resolution of the system.

F. What are the costs?

SAR images are not cheap. Although the systems work at any time of day or night, weather conditions might degrade the image for a very high frequency system. Lower frequency systems are not affected by weather to any great extent, but some arrangement should be made to pay only for those images that are useful.

G. What is the best flight path for this particular problem?

Certain geologic structures are best viewed from specific angles. A good contractor will suggest the best flight paths for the optimal effect. Sometimes more than one flight might be advisable to add to the confidence of an image due to shadowing or other effect. 
APPENDIX A

BIBLIOGRAPHY 


\section{BIBLIOGRAPHY}

\section{Electromagnetic Inductive Survey Methods}

Benson, R., et al. Geophysical Techniques for Sensing Buried Waste and Waste Migration. EPA Environmental Monitoring Systems Laboratory, Las Vegas, Nevada, 1984.

Cox, S., and W. Saunders. Applications of Electromagnetic and Ground Penetrating Radar Geophysical Techniques for Identifying Zones of Potential Subsurface Contamination. Ground Water Management, 4th National Outdoor Action Conference on Aquifer Restoration, Ground Water Monitoring, and Geophysical Methods, Las Vegas, Nevada, 1990, p. 1035.

Dighem Surveys \& Processing Inc. Dighem IV EM Systems Specifications. Dighem Surveys \& Processing Inc., Ontario, Canada, 1971.

Fraser, D. "Layered Earth Resistivity Mapping." U.S. Geological Survey Bulletin, Number 1925, 1990.

Fraser D. "The Multicoil Airborne Electromagnetic System." Geophysics, Vol.44, No.8, 1979, p. 1381.

Geonics Limited Inc. Geonics Electromagnetic Instrumentation Applied to Groundwater Contamination. Unpublished report mailed with product literature, Geonics Limited, Mississauga, Ontario, Canada, 1990.

McNeill, J. Electromagnetic Terrain Conductivity Measurements at Low Induction Numbers. Unpublished report mailed with product literature, Geonics Limited, Mississauga, Ontario, Canada, 1980.

Parasnis, D. Mining Geophysics. Elsevier Publishing Co., New York, New York, 1966.

Schife, J. "Using Geophysical Technical Techniques in Environmental Site Assessments." Municipal \& Industrial Water \& Pollution Control, CXXVII, August, 1990, pp. 4-5.

Sinha, A. "Comparison of Airborne EM Coil Systems Placed Over a Mulitlayer Conductive Earth." Geophysics, Vol. 38, No. 5, 1973, pp. 894-919.

Telford, W. M., et al. Applied Geophysics. Cambridge University Press, Cambridge, Mass., 1976.

\section{Gravimetry}

Fajklewicz, Z. J. "Gravity Vertical Gradient Measurements for the Detection of Small Geologic and Anthropogenic Forms." Geophysics, Vol. 41, 1976, p. 1016.

Hammer, S. "Estimating Ore Masses in Gravity Prospecting." Geophysics, Vol. 10, 1945, p. 50.

Jordan, S. "Moving-Base Gravity Gradiometer Surveys and Interpretation." Geophysics, Vol. 43, 1978, p. 94. 
La Fehr, T. R. "Gravity Method." Geophysics, Vol. 45, 1980, p. 1634.

Torge, W. Gravimetry. Walter de Gruyter Co., Berlin, Germany, 1989.

Telford, W. M., et al. Applied Geophysics. Cambridge University Press, Cambridge, Mass., 1976.

\section{Ground-Penetrating Radar}

Annan, A., et al. "Radar Soundings in Potash Mines, Saskatchewan, Canada." Geophysics, Vol. 53, No. 12, 1988, pp. 1556-1561.

Arcone, S. "Distortion of Model subsurface Radar Pulses in Complex Dielectrics." Radio Science, Vol. 16, No. 5, 1981 , pp. 855-864.

Fenner, T., and S. Smith. Hazardous Waste Investigations Utilizing Subsurface Interface Radar. Unpublished report mailed with personal correspondence from Mr. Edgar of Geophysical Survey Systems, Inc., August 8, 1991.

Meneghini, R., et al. "Analysis of a Dual-Wavelength Surface Reference Radar Technique." IEEE Transactions on Geoscience and Remote Sensing, Vol. GE-25, No. 4, 1987, pp. 456-471.

Michiguchi, Y., et al. "Development of Signal Processing Methods for Imaging Buried Pipes." IEEE Transactions on Geoscience and Remote Sensing, Vol. GE-25, No. 1, 1987, pp. 11-15.

Mitchel, M. Personal conversation about the capabilities of the airborne GPR system flown by Airborne Environmental Surveys, Inc. Santa Maria, California, July 31, 1991.

Vaughn, C. "Ground-Penetrating Radar Surveys used in Archaeological Investigations." Geophysics, Vol. 51, No. 3, 1986, pp. 595-604.

\section{Magnetometry}

Breiner, S. Applications Manual for Portable Magnetometers: EG\&G Geometrics, Sunnyvale, California, 1973.

DeReamer, J. and D. Pierce. Geophysical Investigation for Buried Drums: A Case Study. EG\&G Geometrics, Sunnyvale, California.

EG\&G Geometrics. Airborne Detection of Anomalies Produced by Chemical Alterations over Oil and Gas Deposits. EG\&G Geometrics, Sunnyvale, California, 1984.

Fowler, J.W., et al. Detection of Buried Drums and Tanks at Waste Disposal Sites and Industrial Plants. EG\&G Geometrics, Sunnyvale, California.

Henderson, R. and Y. Miyazaki. "Direct Indication of Hydrocarbons from Airborne Magnetics." Journal of Exploration Geophysics, Vol. 15, 1984, pp. 213-219.

Johnston, R. B. Proton Magnetometry and its Application to Archaeology; An Evaluation at Angle Site. Indiana Historical Society, Indianapolis, Indiana, 1964.

Smith, B. D. Helicopter Geophysical Survey to Detect Brine, Brookhaven Oil Field, Ms. EPA TIP \#89-8495, 1989. 


\section{Synthetic Aperture Radar}

Bartsch, N., et al. "Contributions to Oil-Spill Detection and Analysis with Radar and Microwave Radiometry: Results of the Archimedes II Campaign" IEEE Transactions on Geoscience and Remoie Sensing, Vol. GE-25, No. 6., 1987.

Curlander, J. "Utilization of Spaceborne SAR Data for Mapping." IEEE Transactions on Geoscience and Remote Sensing, Vol. GE-22, No. 2, 1984, pp. 106-112.

Harger, R. Synthetic Aperture Radar Systems: Theory and Design. Academic Press, New York, New York, 1970.

Jensen, H., et al. "Side Looking Airborne Radar." Scientific American, October 1977, p. 84.

Lim, H., et al. "Clarification of Earth Terrain Using Polarimetric Synthetic Aperture Radar Images." Journal of Geophysical Research, Vol. 94, No. B6, June 1989, pp. 7049-7057.

Liu, K. "Real-Time Processor for Synthetic-Aperture Radar." NASA Technical Briefs, Vol. 12, No. 3, Item \#127, March 1988.

Moore, R. Personal correspondance which included a paper about use of SAR. University of Kansas Radar Systems and Remote Sensing Laboratory, Lawrence, Kansas, August 5 , 1991.

van Zyl, J., and H. Zebker. "Status of Imaging Radar Polarimetry." NASA Technical Briefs, Vol. 15, No. 1, Item \#107, January 1991.

Wagner, P. Personal correspondence describing the capabilities of the P-3/SAR system operated by the Environmental Research Institute of Michigan (ERIM). Ann Arbor, Michigan, August 7, 1991.

Wirin, W. Personal correspondence describing the capabilities of the Russian fleet of satellite SAR instruments called ALMAZ. ALMAZ Corporation, Colorado Springs, Colorado, August 2, 1991.

Zoughi, R., et al. "Evaluation and Comparison of Dominant Backscattering Sources at $10 \mathrm{GHz}$ in Two Treatments of Tall-Grass Prairie." Remote Sensing of the Environment, No. 22, 1987. 
APPENDIX B

GLOSSARY 


\section{GLOSSARY}

\section{Anomaly}

Unusual or abnormal readings that differ from expected values.

\section{Anomaly Wavelength}

The distance from where a target is first detected at a predetermined level to where it is no longer detectable.

\section{Amplitude}

The extent to which an alternating or pulsating current or voltage swings from zero or from a mean value.

\section{Attenuation}

The decrease in amplitude of a signal during its transmission from one point to another. It is measured in units of $\mathrm{dB}$ per meter.

\section{Bandwidth}

Range or variance of frequencies.

\section{Bird}

A torpedo-shaped cylinder which is used to house the airborne electronics of an EMI system. It is usually towed by a cable attached behind the helicopter. A single bird may also hold the electronics for other geophysical prospecting toois such as a Magnetometer.

\section{Conductance}

The relative ability of a substance to allow a current flow. A higher value indicates a greater ability for current flow.

\section{Conductor}

A substance which readily allows the flow of electric current through it. The unit of measure of conductance is the mho per meter. When a voltage potential difference of one volt is placed across a substance which has a conductance of one mho, it will produce an electric current of one ampere. The larger the conductance, the better the conductor. Typical conductance values for some common materials are:






\section{Correction Factors}

Mathematical techniques and artificial references which have been developed to eliminate specific factors from the survey data (centrifugal effect, the tidal effect, local topographical effects) so that normalized data can be determined. Examples of correction factors in gravimetry are the free-air anomaly, the Bouguer anomaly, the reference sphere, and the geoid.

\section{Cultural Noise}

Objects that cause electromagnetic fields which interfere with the detection of survey targets. These may include steel-reinforced concrete, fences, metal buildings, or a nearby radio transmitter.

\section{Density}

The mass per unit volume. The specific gravity of a body is the ratio of a density to the density of a standard substance, i.e., air or water. Gravimetry, for example, can determine the changes in density of the subsurface environment, which could be used to locate the perimeters of landfills, the depth to an aquifer, or the stratification of the subsurface geology. Typical density values for some common materials are:

$$
\begin{aligned}
& \text { Quartz ........... } 2.6 \mathrm{~g} / \mathrm{cm}^{3} \\
& \text { Sandstone ........ } 2.3 \mathrm{~g} / \mathrm{cm}^{3} \\
& \text { Brown coal ........ } 1.2 \mathrm{~g} / \mathrm{cm}^{3} \\
& \text { Granite .......... } 2.7 \mathrm{~g} / \mathrm{cm}^{3} \\
& \text { Rock salt ......... } 2.2 \mathrm{~g} / \mathrm{cm}^{3}
\end{aligned}
$$

\section{Depth of Penetration}

The depth a fluctuating electromagnetic field will penetrate into the soil. A more conductive soil will have a more shallow depth of penetration. A lower frequency electromagnetic field will have a greater depth of penetration. Coil orientation and separation are also factors.

\section{Dielectric Constant}

An electric property of soil. A major factor in determining the speed of propagation of an electromagnetic pulse through soil.

\section{Diurnal Variations}

Cyclical variation in the Earth's magnetic field of up to 200 gammas during daylight hours.

\section{Electrical Characteristics of Soil}

Here, the dielectric constant and conductance of a soil.

\section{Electromagnetic Pulse (EMP)}

Transmitted energy of short duration having both magnetic and electric properties.

\section{Gal}

Common unit of measure in gravimetry $\left(\mathrm{cm} / \mathrm{s}^{2}\right)$.

\section{Gamma}

A unit of magnetic intensity equal to one nano-tesla or $10^{-5}$ gauss. 


\section{Induction}

The process of establishing an electric cuirent or a magnetic field in a substance by the presence of a fluctuating electromagnetic field.

\section{In-Phase}

Two waves of the same frequency that pass through their maximum and minimum values of like polarity at the same instant are said to be in-phase.

\section{Magnetic Susceptibility}

A material's relative ability to alter a magnetic field.

\section{Overburden}

A conductive upper strata of soil.

\section{Polarity}

Condition by which the direction of the electronic current can be determined.

\section{Precession}

The effect produced when torque is applied to a rotating body, causing it to wobble. The wobbling frequency is determined by the gravitational field strength and the mass of the body.

\section{Proitiling}

A survey technique where measurements are made at predetermined spots along a survey grid at a single frequency. The measurements will then represent the conductive value of the soil at a certain depth between the transmitter and receiver coils. By mapping the measured values, a contour map of the conductance of the soil at specific depthis can be made.

\section{Pulse Width}

The physical distance over which the EMP acts at a specific instant in time. Because the EMP has different velocities in different soil types, the actual width is soil dependent. For this reason, the width is expressed in terms of time duration for the full EMP to pass a specific point. For GPR, pulse widths of 0.5 to 20 nanoseconds are common.

\section{Resolution}

The minimum physical distance at which two objects can be separated and still be distinguished. In GPR, there are two directions of resolution: the horizontal (which includes the velocity of the system as it takes measurements) and the depth (which depends on the pulse width of the EMP).

\section{Sounding}

A survey technique in which measurf ments are made at predetermined spots along a survey grid at different frequencies. The measurements will then represent the conductance of the soil at many different depths. By mapping the data, a three-dimensional map of the subsurface can be made. Sounding could help locate geologic structures such as bedrock iraciures, metallic drums, storage tanks, and aquifers. 


\section{Target}

An object or condition which causes an anomalous reading during a subsurface survey.

\section{Wavelength}

Distance that an electromagnetic wave travels in one complete cycle. 


\section{APPENDIX C}

TARGET SURVEY CHART 
TARGET SURVEY CHART

\begin{tabular}{|c|c|c|c|c|}
\hline Technology & Target Type & $\begin{array}{l}\text { Depth of } \\
\text { Detection }\end{array}$ & $\begin{array}{c}\text { Positive } \\
\text { Attributes }\end{array}$ & $\begin{array}{c}\text { Negative } \\
\text { Attributes }\end{array}$ \\
\hline $\begin{array}{l}\text { Electromagnetic } \\
\text { Inductive }\end{array}$ & $\begin{array}{l}\text { Any metal object } \\
\text { or highly } \\
\text { conductive soil }\end{array}$ & $\begin{array}{l}300 \text { meters for } \\
\text { airborne, } 1000 \\
\text { meters for } \\
\text { ground-based }\end{array}$ & $\begin{array}{l}\text { Can find any } \\
\text { metal } \\
\text { Rapid data } \\
\text { collection }\end{array}$ & Poor resolution \\
\hline Gravimetry & $\begin{array}{l}\text { Sharp changes in } \\
\text { soil density }\end{array}$ & $\begin{array}{l}\text { No actual limit, } \\
\text { but smaller } \\
\text { targets must be } \\
\text { near the } \\
\text { Gravimeter }\end{array}$ & $\begin{array}{l}\text { Simple to use } \\
\text { and understand } \\
\text { Can detect } \\
\text { caverns which } \\
\text { other } \\
\text { technologies can } \\
\text { not }\end{array}$ & $\begin{array}{l}\text { Airborne systems } \\
\text { can only find very } \\
\text { large targets } \\
\text { Very expensive }\end{array}$ \\
\hline $\begin{array}{l}\text { Ground } \\
\text { Penetrating } \\
\text { Radar }\end{array}$ & $\begin{array}{l}\text { Changes in the } \\
\text { electrical } \\
\text { properties of the } \\
\text { subsurface }\end{array}$ & $\begin{array}{l}50 \text { meters for a } \\
\text { ground-based } \\
\text { system, } 20 \\
\text { meters for an } \\
\text { airborne sysem }\end{array}$ & $\begin{array}{l}\text { Preliminary } \\
\text { results available } \\
\text { before data } \\
\text { processing } \\
\text { High resolution }\end{array}$ & $\begin{array}{l}\text { Cannot be used } \\
\text { in areas of } \\
\text { conductive soils } \\
\text { Can require a } \\
\text { great deal of data } \\
\text { collection for a } \\
\text { small area }\end{array}$ \\
\hline Magnetometry & $\begin{array}{l}\text { Any iron-based or } \\
\text { magnetic object } \\
\text { or volume of soil }\end{array}$ & $\begin{array}{l}3 \text { meters for a } \\
55-\text { gallon drum, } \\
\text { up to } 100 \text { meters } \\
\text { for a ship hull }\end{array}$ & $\begin{array}{l}\text { Simple to use } \\
\text { and understand } \\
\text { Can directly } \\
\text { detect objects }\end{array}$ & $\begin{array}{l}\text { Sensitive to } \\
\text { sunspots }\end{array}$ \\
\hline $\begin{array}{l}\text { Synthetic } \\
\text { Aperture } \\
\text { Radar }\end{array}$ & $\begin{array}{l}\text { Geologic } \\
\text { topography, crop } \\
\text { leaf size and } \\
\text { moisture content }\end{array}$ & $\begin{array}{l}\text { Resolutions of } \\
1.5 \text { by } 1.5 \text { meters } \\
\text { for aircraft and } 15 \\
\text { by } 25 \text { meters for } \\
\text { satellite systems }\end{array}$ & $\begin{array}{l}\text { Produces images } \\
\text { of near } \\
\text { photographic } \\
\text { quality, can } \\
\text { image through } \\
\text { crop cover }\end{array}$ & $\begin{array}{l}\text { Very expensive } \\
\text { images }\end{array}$ \\
\hline
\end{tabular}




\section{APPENDIX D}

CONTRACTOR LISTING 


\section{Partial Listing of Potential Contractors \\ for \\ Subsurface Surveys}

While researching information for this publication, the following contractors were contacted on a random basis. In addition to supplying the information used, these companies have consented to the publication of their names as references. EG\&G cannot endorse, nor verify, the abilities of these companies. Time constraints forced this limited contact with contractors, but a more complete listing of contractors can be found in The Geophysical Directory, published in 1991 by The Geophysical Directory, Inc. of Houston, Texas.

\section{Electromagnetic Inductive Surveys}

A. Airborne Surveys:

- Aerodat Limited, Mississauga, Ontario, Canada

- Dighem Surveys \& Prospecting Inc, Mississauga, Ontario, Canada

B. Ground-Based Surveys:

- Fromm Applied Technology, Mequon, Wisconsin

- Zonge Engineering \& Research Organization, Tucson, Arizona

\section{Gravimetry Surveys}

A. Airborne Surveys:

- Carson Services, Inc./Aerogravity Division, Perkasie, Pennsylvania

B. Ground-Based Surveys:

- Austin Exploration, Houston, Texas

- Consolidated Geophysical Surveys, Tulsa, Oklahoma

- Exploration Services Inc., Plano, Texas

- Gravimetrics Inc., Tulsa, Oklahoma

\section{Ground-Penetrating Radar Surveys}

A. Airborne Surveys:

- Airborne Environmental Surveys, Santa Maria, California

B. Ground-Based Surveys:

- Ecology \& Environment, Dallas, Texas

- Environmental Control Technologies, Bedford, New Hampshire

- Harding \& Lawson Associates, Novato, California

- STS Consultants, Northbrook, Illinois

- Subsurface Consulting Limited, New Fairfield, Connecticut

- Subsurface Evaluation, Winter Springs, Florida 


\section{Magnetometry Surveys}

A. Airborne Surveys

- Aero Services, Houston, Texas

- Aerodat Limited, Mississauga, Ontario, Canada

- Airmag Surveys, Inc., Philadelphia, Pennsylvania

- Dighem Surveys \& Prospecting Inc, Mississauga, Ontario, Canada

B. Ground-Based Surveys:

- Austin Exploration, Houston, Texas

- Consolidiated Geophysical Surveys, Tulsa, Oklahoma

- Exploration Services Inc., Plano, Texas

- Zon Je Engineering \& Research Organization, Tucson, Arizona

\section{Synthetic Aperture Radar Surveys}

A. Airborne Surveys:

- Aero Service, Houston, Texas

- Environmental Research Institute of Michigan (ERIM), Ann Arbor, Michigan 
DOE/NV

C. A. Cox

(1)

M.R. Dockter

C.M. Poley

(1)

S.C. Ronshaugen

(1)

R. F. Smiecinski

(2)

(1)

DOE/HQ

OSTI

(25)

\section{EG\&G/EM}

J. F Doyle LVAO (1)

K.W. Forcade LVAO (50)

J.A. Michael LVAO (1)

C.K. Mitchell LVAO (1)

D. Mohr SBO (1)

M.H. Parelman LVAO (1)

L. G. Sasso LVAO (1)

K. A. Taylor LVAO (50)

W. J. Tipton LVAO (1)

P. H. Zavattaro LVAO (1)

\section{LIBRARIES}

RSL

SBO

TIC 



$$
7 / 27 / 93
$$
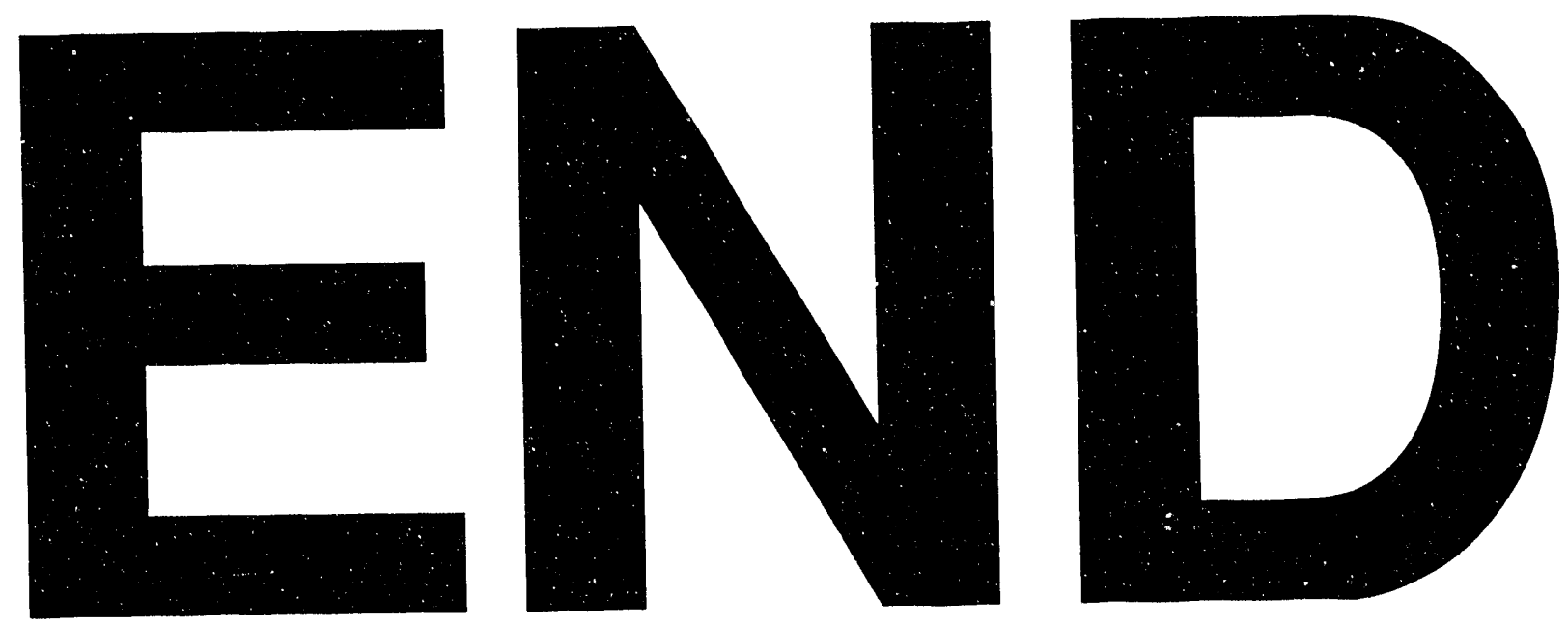
